
Superfícies de Respostas - Parte II: Variáveis de Mistura

Novaes, C. G.; Yamaki, R. T.; de Paula, V. F.; do Nascimento Junior, B. B.; Barreto, J. A.; Valasques, G. S.; Bezerra, M. A.*

Rev. Virtual Quim., 2018, 10 (2), 393-420. Data de publicação na Web: 20 de março de 2018

http://rvq.sbq.org.br

\title{
Optimization of Analytical Methods Using Response Surface Methodology - Part II: Mixture Variables
}

Abstract: The present paper approaches the application of response surface methodology (RSM) in the optimization of mixture variables aiming the development of analytical methods. Some basic principles of this multivariate method are presented and characteristics of the main experimental designs are discussed. Examples of mixture design application for optimization of analytical methods is also presented for illustrated the potentialities of this chemometric tool.

Keywords: Response surface methodology; mixture variables; constrained designs; optimization of analytical methods.

\section{Resumo}

O presente artigo aborda a aplicação da metodologia de superfícies de resposta (MSR) na otimização de variáveis de misturas objetivando o desenvolvimento de métodos analíticos. Alguns princípios básicos desse método multivariado são apresentados e as características dos principais planejamentos experimentais são discutidas. Exemplos de aplicações de planejamento de misturas na otimização de métodos analíticos são também apresentados para ilustrar as potencialidades dessa ferramenta quimiométrica.

Palavras-chave: Metodologia de superfície de respostas; variáveis de mistura; planejamentos com restrições; otimização de métodos analíticos.

\footnotetext{
* Universidade Estadual do Sudoeste da Bahia, Departamento de Ciências e Tecnologias, Campus de Jequié, Rua José Moreira Sobrinho, s/n, CEP 45208-091, Jequié-BA, Brasil.

M mbezerra@uesb.edu.br

DOI: $10.21577 / 1984-6835.20180030$
} 


\title{
Otimização de Métodos Analíticos Usando Metodologia de Superfícies de Resposta - Parte II: Variáveis de Mistura
}

\author{
Cleber G. Novaes, Regina T. Yamaki, Vanderlúcia F. de Paula, Baraquizio
}

B. do Nascimento Junior, Jeferson A. Barreto, Gisseli S. Valasques, Marcos A. Bezerra*

Universidade Estadual do Sudoeste da Bahia, Departamento de Ciências e Tecnologias, Campus de Jequié, Rua José Moreira Sobrinho, s/n, CEP 45208-091, Jequié-BA, Brasil.

*mbezerra@uesb.edu.br

Recebido em 17 de novembro de 2017. Aceito para publicação em 12 de março de 2018

1. Introdução

2. Modelos matemáticos para descrição de misturas

3. Domínio experimental em planejamentos de misturas

4. Tipos de planejamentos de misturas

4.1. Planejamentos em rede simplex

4.2. Planejamentos centroide-simplex

5. Exemplo de aplicação da MSR na otimização de variáveis de misturas

6. Misturas com restrições

6.1. Misturas com limites inferiores

6.2. Misturas com limites inferiores e superiores

7. Exemplos de aplicação da MSR na otimização de misturas com restrições

8. Planejamento de misturas na otimização de procedimentos analíticos

9. Conclusões

\section{Introdução}

As técnicas de otimização são particularmente utilizadas em química analítica quantitativa com o intuito de melhorar as características de um procedimento ou de um método, de forma a torná-lo mais eficiente, mais sensível e mais apto a desempenhar sua função, que é a determinação confiável de analitos em diversas matrizes. ${ }^{1}$

As variáveis (ou fatores) que influenciam o desempenho de um experimento podem ser classificadas em variáveis de processo ou variáveis de mistura. As matrizes experimentais utilizadas para otimizar as variáveis de processo permitem a 
combinação independente de seus níveis livre de restrições relativas à proporção. No entanto, ao contrário desses planejamentos, as matrizes para otimização de variáveis de misturas dependem das proporções dos seus componentes. Os planejamentos de misturas são particularmente usados quando se tem que lidar com a combinação entre os níveis das proporções. A resposta medida na aplicação de um planejamento para otimização de misturas é função das proporções de cada componente. ${ }^{2,3}$

A equação 1 mostra que a combinação dos i componentes não podem exceder $100 \%$ (ou a unidade). Por exemplo, para três componentes, se a proporção de $x_{1}$ e $x_{2}$ é estabelecida, então a proporção de $x_{3}$ deve ser $100-\left(x_{1}+x_{2}\right)$. Sendo assim, pode-se dizer que os níveis das variáveis que compõem este tipo de planejamento são dependentes, pois para especificar a composição da mistura de $\mathrm{k}$ componentes, só precisamos fixar as proporções de $k-1$ componentes, havendo perda de um grau de liberdade. ${ }^{4}$

$$
\sum_{\mathrm{i}=1}^{k} \mathrm{X}_{\mathrm{i}}=100 \%=1
$$

Eq. 1

As matrizes experimentais para otimização de misturas possuem grande capacidade no desenvolvimento de métodos analíticos, pois permitem estudar de forma mais completa e racional a influência da proporção de cada componente em uma mistura utilizada em alguma etapa de um método e melhorar seu desempenho. No entanto, estes planejamentos ainda são raramente usados na otimização de métodos analíticos, embora apresentem grande potencial para isso. Suas principais aplicações nessa área são a otimização da proporção de componentes de fases móveis em cromatografia líquida, mas essa ferramenta quimiométrica pode ser usada visando outras aplicações.

Esta segunda parte da revisão sobre metodologia de superfície de resposta ${ }^{63}$ discute a utilização de matrizes experimentais para otimização de misturas no desenvolvimento de métodos analíticos. Serão abordados os princípios e características destes tipos de planejamentos, além do estabelecimento de restrições aos componentes da mistura. Serão apresentados também exemplos da literatura que ilustram a aplicação desta técnica de otimização.

\section{Modelos matemáticos para descrição de misturas}

As bases para a aplicação da MSR na modelagem de dados provenientes de planejamentos de misturas foram estabelecidas por Scheffé em 1958. ${ }^{11}$ Seu método para investigar as propriedades de sistemas multicomponentes em função de sua composição se constitui nos fundamentos desse campo que vem sendo aplicados na otimização dos mais variados experimentos que envolvem misturas. Para descrever o comportamento das propriedades desses sistemas, Scheffé introduziu modelos polinomiais apropriados para o ajuste de funções matemáticas que demandam um número mínimo de pontos exatamente iguais ao número de termos do polinômio a ser usado. ${ }^{2,6}$ Considere as equações 2 e 3 usadas para predizer a resposta em função dos valores adotados para duas variáveis independentes, em que se pode assumir qualquer combinação entre seus níveis.

$$
\begin{array}{ll}
y=b_{0}+b_{1} x_{1}+b_{2} x_{2} & \text { Eq. } 2 \\
y=b_{0}+b_{1} x_{1}+b_{2} x_{2}+b_{11} x_{1}^{2}+b_{22} x_{2}^{2}+b_{12} x_{1} x_{2} & \text { Eq. } 3
\end{array}
$$


Estas equações não são adequadas para a descrição de misturas. Lembrando-se que, em uma mistura binária tem-se a relação $x_{1}+$ $x_{2}=1$, pode-se reescrever a equação 2 , como apresentado nas equações 4 a 6 :

$$
\begin{array}{ll}
y=b_{0}\left(x_{1}+x_{2}\right)+b_{1} x_{1}+b_{2} x_{2} & \text { Eq. } 4 \\
y=\left(b_{0}+b_{1}\right) x_{1}+\left(b_{0}+b_{2}\right) x_{2} & \text { Eq. } 5 \\
y=b^{\prime}{ }_{1} x_{1}+b^{\prime}{ }_{2} x_{2} & \text { Eq. } 6
\end{array}
$$

Há agora dois coeficientes para quadráticos como na Eq. 3, pode-se também determinar $b^{\prime}{ }_{1}$ e $b^{\prime}$.

Se a equação apresentar termos

$$
\begin{array}{ll}
y=b_{0}+b_{1} x_{1}+b_{2} x_{2}+b_{11} x_{1}{ }^{2}+b_{22} x_{2}{ }^{2}+b_{12} x_{1} x_{2} & \text { Eq. } 3 \\
y=\left(x_{1}+x_{2}\right) b_{0}+b_{1} x_{1}+b_{2} x_{2}+b_{11} x_{1}\left(1-x_{2}\right)+b_{22} x_{2}\left(1-x_{1}\right)+b_{12} x_{1} x_{2} & \text { Eq. } 7 \\
y=\left(b_{0}+b_{1}+b_{11}\right) x_{1}+\left(b_{0}+b_{2}+b_{22}\right) x_{2}+\left(b_{12}-b_{11}-b_{22}\right) x_{1} x_{2} & \text { Eq. } 8 \\
y=b^{\prime}{ }_{1} x_{1}+b^{\prime}{ }_{2} x_{2}+b^{\prime}{ }_{12} x_{1} x_{2} & \text { Eq. } 9
\end{array}
$$

A equação 9 agora apresenta apenas três (ao invés de seis) coeficientes para determinar $b^{\prime}{ }_{1}$ e $b^{\prime}{ }_{2}$ e $b^{\prime}{ }_{12}$.

Os modelos para misturas contendo mais de dois componentes são extensões dos modelos de dois componentes. Assim, para $\mathrm{k}$ componentes, pode-se desenvolver um modelo linear, quadrático, cúbico completo e cúbico especial. ${ }^{4,5} \mathrm{Na}$ prática a aplicação do modelo cúbico completo é muito trabalhosa, pois exige, por exemplo, no caso de três variáveis, no mínimo dez experimentos diferentes para a estimativa de todos os seus coeficientes. Geralmente a presença de apenas um termo cúbico é suficiente para descrever satisfatoriamente a região experimental estudada e, desta forma, o modelo cúbico especial é preferido. As expressões gerais apresentadas nas equações 10 a 13 podem ser aplicadas no desenvolvimento de modelos com uma quantidade $\mathrm{k}$ de componentes. $^{6}$

O modelo matemático linear é o mais simples que pode ser utilizado. Nele se assume que nenhum efeito de interação exista entre as variáveis, ou seja, o comportamento da resposta depende apenas da proporção dos componentes na mistura agindo um independente do outro. Para sua modelagem, basta a realização de experimentos com os componentes puros, mas ele deve ser validado com pontos adicionais. Se a aplicação do modelo linear não for eficiente para descrever o comportamento da mistura em todo domínio experimental estudado, então se deve partir para um modelo matemático mais adequado e também mais complexo. ${ }^{3,5}$ Sendo assim, a resposta obtida pela mistura real dos dois componentes pode ser maior ou menor do que esperado pela simples contribuição proporcional de cada componente na mistura. No primeiro caso temos um efeito sinérgico e no segundo, um efeito antagônico. Para descrição desses efeitos utiliza-se um modelo quadrático ou superior.

Após a obtenção das respostas correspondentes a cada ponto definido pela matriz experimental, os coeficientes $\mathbf{b}$ dos modelos matemáticos podem ser estimados usando-se o método dos mínimos quadrados que, na forma matricial, é expresso pela equação 14. 


$$
\begin{aligned}
& y=\sum_{i=1}^{k} b_{i}^{\prime} x_{i} \text { (modelo linear) } \\
& y=\sum_{i=1}^{k} b_{i}^{\prime} x_{i}+\sum_{i<j}^{k} \sum_{j}^{k} b_{i j}^{\prime} x_{i} x_{j} \quad \text { (modelo quadrático) } \\
& y=\sum_{i=1}^{k} b_{i}^{\prime} x_{i}+\sum_{i<j}^{k} \sum_{j}^{k} b_{i j}^{\prime} x_{i} x_{j}+\sum_{i<j}^{k} \sum_{j}^{k} b_{i j}^{\prime} x_{i} x_{j}\left(x_{i}-x_{j}\right)+\sum_{i<j}^{k} \sum_{j<k}^{k} \sum_{k}^{k} b_{i j k}^{\prime} x_{i} x_{j} x_{k} \\
& \text { (modelo cúbico completo) } \\
& \text { Eq. } 12 \\
& y=\sum_{i=1}^{k} b_{i}^{\prime} x_{i}+\sum_{i<j}^{k} \sum_{j}^{k} b_{i j}^{\prime} x_{i} x_{j}+\sum_{i<j}^{k} \sum_{j<k}^{k} \sum_{k}^{k} b_{i j k}^{\prime} x_{i} x_{j} x_{k} \\
& \text { (modelo cúbico especial) } \\
& B=\left(X^{\top} X\right)^{-1}\left(X^{\top} Y\right)
\end{aligned}
$$

em que $\mathrm{Y}$ é o vetor coluna de dimensão ( $\mathrm{N} \mathrm{X}$ 1), que contém os valores das respostas para cada ponto experimental da matriz executada para cada mistura. Cada linha da matriz $\mathbf{X}$, de dimensão $(\mathrm{N} \times \mathrm{p})$, corresponde a uma mistura e contém a mesma ordem vertical no vetor $\mathbf{Y}$, enquanto $\mathbf{B}$ é um vetor coluna de dimensão $(p \times 1)$ formado pelos coeficientes do modelo que deseja-se ajustar aos dados, sendo $\mathrm{p}$ o número de parâmetros da sua função matemática.

$$
\operatorname{Var}(B)=\left(X^{\top} X\right)^{-1} s^{2}
$$

Em que $s^{2}$ é a variância global associada às medidas replicadas realizadas em relação aos experimentos definidos pela matriz experimental. ${ }^{5}$ Para maiores informações sobre como usar os parâmetros da Análise de Variância (ANOVA) para avaliar os modelos matemáticos ajustados aos dados, consultar a parte I dessa revisão. ${ }^{63}$
Para avaliar o nível de significância dos coeficientes $b$, as estimativas dos seus erros devem ser determinadas. Dessa forma, assumindo-se que os erros são independentes entre si e uniformemente distribuídos, a estimativa das variâncias dos coeficientes pode ser obtida usando-se a diagonal principal da matriz de variância e covariância dos elementos que compõem o vetor $B$, de dimensão $(p \times p)$, conforme equação 15 .

Eq. 15

\section{Domínio experimental em planejamentos de misturas}

A Figura 1 apresenta as representações gráficas para os planejamentos de mistura com dois, três e quatro componentes. Para duas variáveis, o planejamento de misturas pode ser representado por uma linha, para três variáveis por um triângulo equilátero e para quatro variáveis por um tetraedro. ${ }^{4,7}$ Acima de quatro componentes estes 
planejamentos são representados em espaços abstratos de dimensões maiores que três. Algebricamente é possível trabalhar com misturas com um número muito grande de componentes, porém sua aplicação prática é mais rara, pois a visualização e interpretação desses sistemas tornam-se mais complexo.

Como o próprio nome diz, as misturas binárias são misturas que envolvem a combinação de dois componentes e seu domínio experimental é representado por uma linha. Qualquer ponto na extremidade dessa linha representa o componente puro e qualquer ponto no interior dessa linha, uma mistura binária.

Considere o modelo linear para mistura binária $y=b^{\prime}{ }_{1} x_{1}+b^{\prime}{ }_{2} x_{2}$. Quando se tem $x_{1}=1$, obrigatoriamente $x_{2}=0$ então $y_{1}=b^{\prime}{ }_{1}$. Por outro lado, quando se tem $x_{1}=0$, obrigatoriamente $x_{2}=1$ então $y_{2}=b^{\prime}{ }_{2}$. Ou seja, as próprias respostas se constituem nos coeficientes do modelo linear. Como não há interação entre os componentes, a superfície de resposta para esta mistura é uma linha reta. Mas, apesar de se poder ajustar o modelo linear tendo-se apenas os resultados para os componentes puros, torna-se necessário verificar a real adequação deste modelo ao sistema estudado fazendo-se, pelo menos, um experimento com uma mistura entre os dois componentes (recomenda-se o ponto onde ter-se-á metade de cada um dos componentes). Verificandose a ineficiência de previsão do modelo linear, se poderá utilizar um modelo mais adequado. $^{4}$

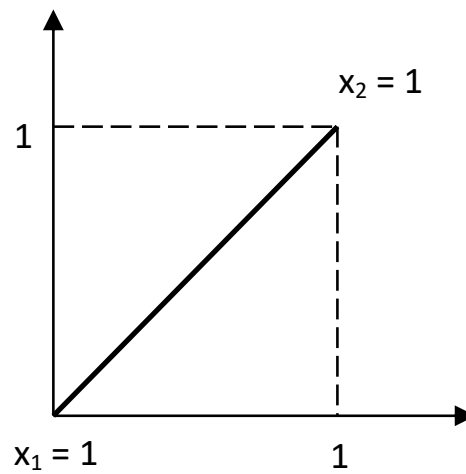

(a)

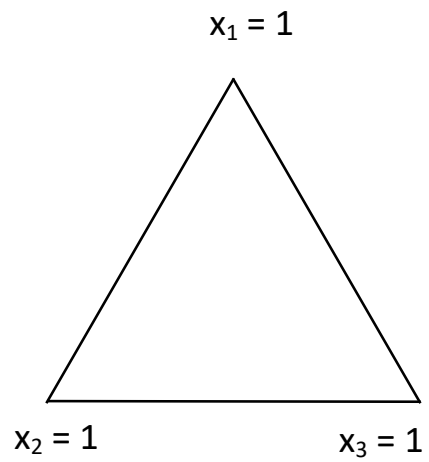

(b)

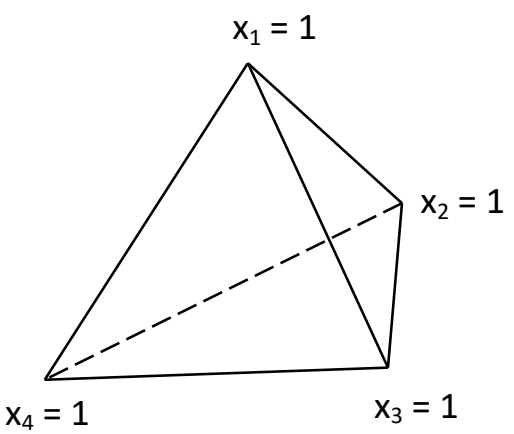

(c)

Figura 1. Representações gráficas de planejamentos de (a) uma mistura binária, (b) uma mistura ternária e (c) uma mistura quaternária

Modelagens de misturas ternárias são muito utilizadas por possuir algumas vantagens como a facilidade de interpretação gráfica e possibilidade de fácil eliminação de um componente, se este não apresentar efeito significativo. O domínio de um planejamento de mistura para três componentes é representado por um triângulo equilátero em que os pontos localizados nos vértices desse triângulo representam os componentes puros, os pontos localizados nos lados representam as misturas binárias e os vértices localizados no interior do triângulo representam misturas onde os três componentes estão presentes. $^{9,10}$

No caso das misturas quaternárias, os vértices representam os componentes puros; qualquer ponto localizado nas arestas representa uma mistura binária; pontos 
localizados em qualquer lado representam misturas ternárias e pontos no interior do tetraedro representam experimentos onde os quatro componentes estão presentes. A Figura 2 mostra os pontos experimentais mínimos necessários para o ajuste desses modelos em planejamentos para misturas ternárias e quaternárias. ${ }^{2,4,12}$

\section{Tipos de planejamentos de misturas}

A escolha de um planejamento de misturas apropriado necessita levar em consideração algumas questões, tais como o número de variáveis e interações a serem estudadas, a complexidade de cada planejamento, a validade estatística, a efetividade na modelagem dos dados e a viabilidade e custos envolvidos em sua execução. ${ }^{8}$ Nos tópicos seguintes, os tipos de planejamentos de misturas mais usados são descritos.

\subsection{Planejamentos em rede simplex}

O planejamento introduzido por Scheffé para a modelagem de misturas no seu trabalho pioneiro de 1958 foi o chamado planejamento em rede simplex ${ }^{11}$. A rede simplex pode ser considerada o equivalente do planejamento fatorial para variáveis de processo no sentido em que os pontos experimentais são tomados nas extremidades do domínio experimental e, para mais de dois níveis, são uniformemente espaçados ao longo das coordenadas que representam as variáveis. $^{8}$

Esse planejamento de mistura consiste em uma rede do tipo $(k, m)$, para $k$ componentes para o ajuste de um polinômio de grau $\mathrm{m}$, em que se pode tomar m-1 pontos experimentais igualmente espaçados entre os níveis 0 e 1 de acordo com a equação 16 :

$$
x_{i}=0, \frac{1}{m}, \frac{2}{m}, \frac{m-1}{m}, 1 \text { para } \mathrm{i}=1,2, \ldots, \mathrm{k} \quad \text { Eq. } 16
$$

Dessa forma, para o ajuste de uma equação de primeiro grau, tem-se apenas os níveis 0 e 1 (Figura 2a e 2e). Para um modelo de segundo grau $(m=2)$ tem-se os níveis 0 , $1 / 2$ e 1 (Figura $2 \mathrm{~b}$ e $2 \mathrm{f}$ ) e para um modelo cúbico $(m=3)$ tem-se os níveis $0,1 / 3,2 / 3$ e 1
(Figura 2d e 2h).

Para o caso geral de $\mathrm{k}$ componentes e $\mathrm{m}$ graus do polinômio a ser ajustado, o número de pontos experimentais para um planejamento completo é dado pela equação 17.

$$
\left(\frac{m+k-1}{m}\right)=\frac{(m+k-1) !}{(k-1) ! m !}
$$


Misturas ternárias

(a)

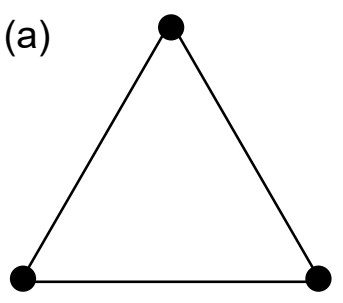

(b)

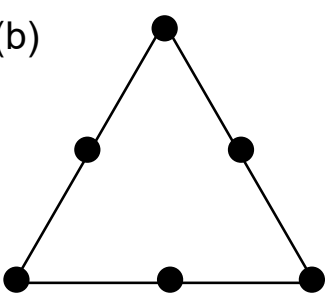

(c)

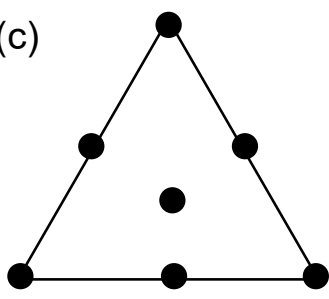

(d)

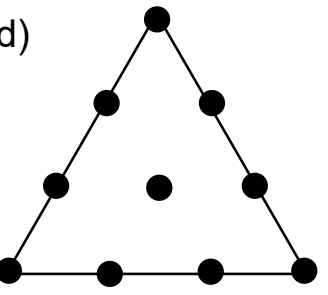

Misturas quaternárias

(e)

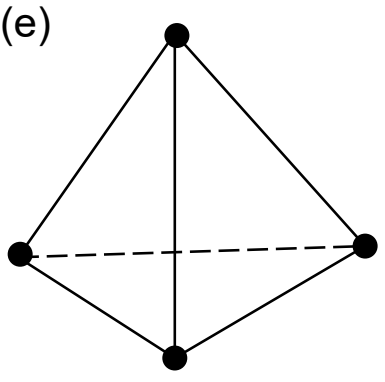

(f)

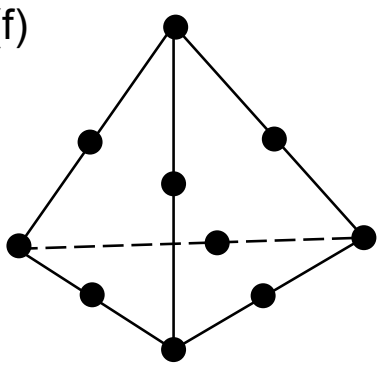

(g)

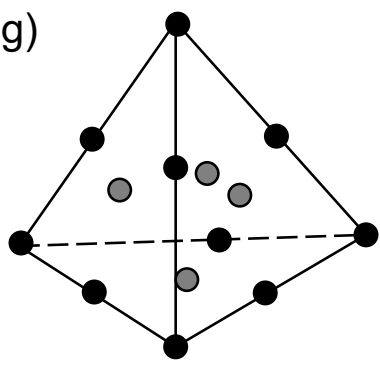

(h)

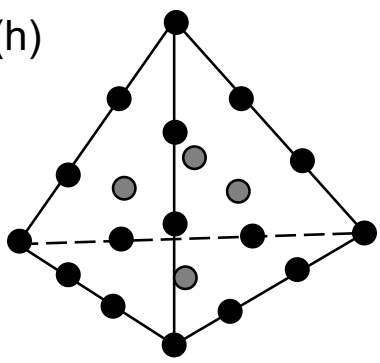

(i)

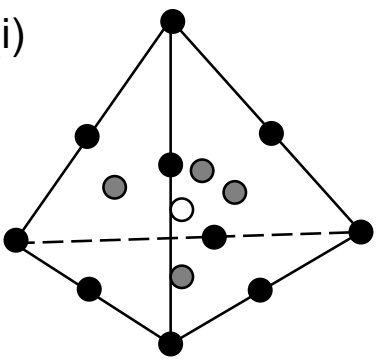

Figura 2. Pontos experimentais mínimos para modelagem de misturas ternárias e quaternárias: (a e e) modelo linear, (b e f) modelo quadrático, (c e g) modelo cúbico especial, ( $\mathrm{d}$ e h) modelo cúbico completo e (i) modelo cúbico especial com um termo de quarta ordem para descrever o efeito na presença dos quatro componentes. Pontos adicionais (não mostrados) podem ser escolhidos para validação do modelo

Os planejamentos em rede simplex apresentam as seguintes desvantagens: (a) demandam um número cada vez maior de pontos experimentais à medida que o grau do polinômio aumenta, o que consequentemente torna mais dispendiosa sua aplicação; e (b) os coeficientes do modelo matemático são calculados com base em dados experimentais onde apenas misturas com $k^{\prime}$ componentes $\left(k^{\prime} \leq k\right)$ estão envolvidos 
(componentes puros e misturas binárias). Esse fato é particularmente evidente para modelos do primeiro grau, onde se realiza apenas experimentos para os componentes puros da mistura. ${ }^{2,8}$

\subsection{Planejamentos centroide-simplex}

Para superar as limitações dos planejamentos em rede simplex, Scheffé em 1963 apresentou um novo planejamento de misturas denominado planejamento centroide simplex. ${ }^{11}$ Esse planejamento permite reduzir o número de coeficientes de um modelo e, consequentemente, o número de pontos experimentais, levando a uma maior economia de tempo e reagentes. Foi proposta uma função polinomial, chamada de modelo cúbico especial, a qual foi formulada para conter apenas os termos que representem os pontos experimentais relacionados à presença de componentes em proporções iguais no interior do espaço experimental delimitado. Em outras palavras, ao menos um ponto central será incluído no planejamento para permitir modelar e avaliar a influência dos possíveis efeitos sinérgicos ou antagonísticos que aparecem na presença de todos os componentes da mistura. Nesse tipo de planejamento o número de pontos experimentais e sua configuração permite que o modelo mais complexo a ser ajustado seja o cúbico especial. Adicionalmente, pontos extras no interior do domínio experimental (representando misturas terciárias, quaternárias...) podem ser usados para avaliar o modelo e até mesmo para ajustar o modelo cúbico completo. ${ }^{2}$ As Figuras $2 \mathrm{c}, 2 \mathrm{~g}$ e $2 \mathrm{i}$ são exemplos de pontos experimentais obtidos em planejamentos de misturas centroide simplex.

Infelizmente, o planejamento centroide simplex ainda possui algumas desvantagens apresentadas pelo planejamento em rede simplex. Apesar do número de termos da equação do modelo especial ser menor que o modelo cúbico completo, o número de pontos também cresce rapidamente com o aumento de k. A maior parte das observações é coletada para misturas compostas de $\mathrm{k}^{\prime}$ componentes $\left(k^{\prime} \leq k\right)$ em pontos do planejamento localizados nas extremidades do domínio experimental e essa característica afeta a representatividade do domínio estudado a menos que se adicione mais pontos coletados no interior do domínio como já comentado anteriormente. ${ }^{11}$

\section{Exemplo de aplicação da MSR na otimização de variáveis de misturas}

Santos et al. ${ }^{57}$ aplicaram planejamento de misturas centróide simplex na otimização da proporção de soluções extratoras em um procedimento de extração assistida por ultrassom para determinação de nove elementos ( $\mathrm{Ba}, \mathrm{Ca}, \mathrm{Cu}, \mathrm{Fe}, \mathrm{K}, \mathrm{Mg}, \mathrm{Mn}, \mathrm{Sr}$ e $\mathrm{Zn}$ ) em amostras de feijões usando espectrometria de emissão óptica com plasma indutivamente aplicado (ICP OES). A Figura 3 apresenta a região experimental estudada por esse planejamento. Cada ponto representa uma combinação de diferentes proporções das soluções que compõem a fase extratora, sendo a soma final igual a 10,0 $\mathrm{mL}$. Os valores de algumas variáveis de processo foram fixados, como a concentração de cada solução ácida $\left(1 \mathrm{~mol} \mathrm{~L}^{-1}\right)$, o tamanho da partícula $(<300 \mu \mathrm{m})$ e o tempo de sonicação (15 min). As respostas avaliadas foram as percentagens de extração por comparação dos resultados obtidos com o procedimento proposto e os resultados obtidos usando-se um procedimento de referência (a digestão assistida por microondas em frascos pressurizados). 


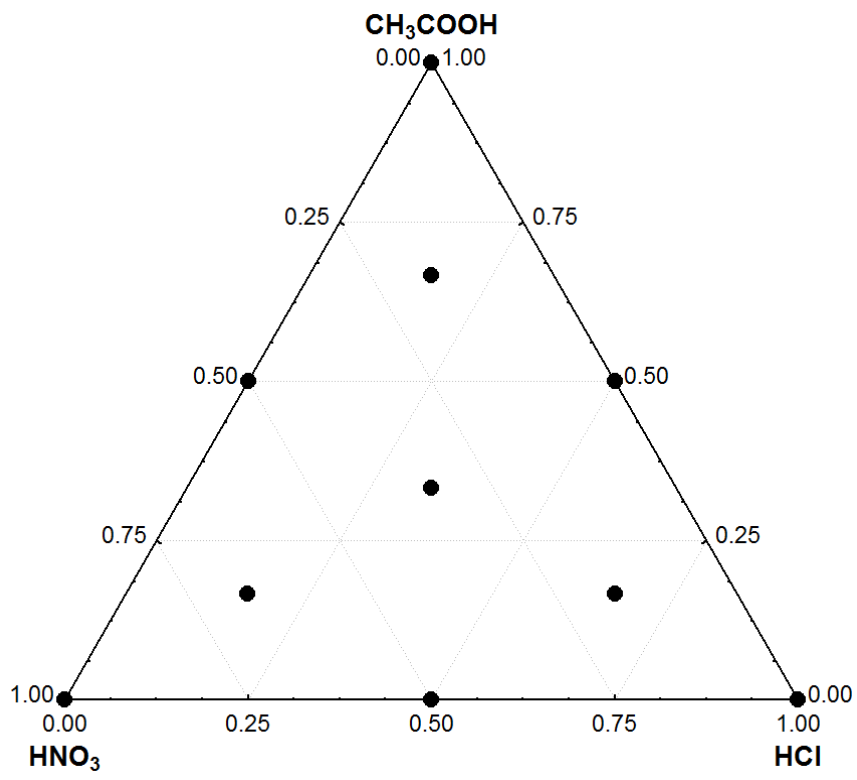

Figura 3. Pontos experimentais do planejamento centroide simplex aplicado à otimização das proporções das soluções de agentes extratores dos metais em amostras de feijões

Para encontrar condições que satisfaça a extração simultânea e eficiente de todos os metais estudados adotou-se a resposta global, a qual é a combinação das nove respostas correspondentes à recuperação de cada metal. A resposta global $(R G)$ é dada pela equação 18 .

$$
R G=[R(X 1) / M R(X 1)+R(X 2) / M R(X 2)+\ldots+R(X n) / M R(X n)]
$$

Em que $R(X n)$ é a resposta para um elemento em um experimento particular e $M R(X n)$ é a maior resposta observada em um conjunto de experimentos para o elemento n. Os resultados são apresentados na Tabela 1.

Ao conjunto de respostas globais obtidas ajustaram-se funções matemáticas (linear, quadrática, cúbica completa e cúbica especial) a fim de descrever adequadamente o comportamento dos dados para que se possam realizar previsões estatísticas válidas.

Para avaliação dos modelos matemáticos ajustados usou-se a Análise de Variância (ANOVA) adotando-se o intervalo de confiança de $95 \%$. Segundo a ANOVA, os modelos quadrático $(p=0,1996)$, cúbico especial $(p=0,1514)$ e cúbico completo $(p=$ $0,8370)$, ao contrário do modelo linear $(p=$ $0,002945)$, apresentaram falta de ajuste não significativa $(p>0,05)$. A expansão do modelo matemático pela adição de termos cúbicos diminui os resíduos deixados em relação ao modelo quadrático, porém o aumento da complexidade do modelo matemático não compensa o pequeno ganho na capacidade de previsão do modelo. Dessa forma, o modelo quadrático foi escolhido no estabelecimento das proporções ótimas entre as soluções extratoras. 
Tabela 1. Planejamento de misturas aplicado na otimização de um método para extração assistida por ultrassom de macro e micro elementos em amostras de feijões

\begin{tabular}{ccccc}
\hline \multirow{2}{*}{ Experimento } & \multicolumn{3}{c}{ Variáveis } & \multirow{2}{*}{ Resposta Global } \\
\cline { 2 - 4 } & $\mathrm{HNO}_{3}$ & $\mathbf{H C l}$ & $\mathbf{C H}_{3} \mathbf{C O O H}$ & \\
\hline 1 & 0,1667 & 0,6667 & 0,1667 & $7,21 / 6,77$ \\
2 & 0,6667 & 0,1667 & 0,1667 & $7,31 / 6,63$ \\
3 & 0,3333 & 0,3333 & 0,3333 & $7,57 / 7,40$ \\
4 & 0,0000 & 0,5000 & 0,5000 & $8,06 / 8,03$ \\
5 & 0,0000 & 1,0000 & 0,0000 & $6,47 / 6,74$ \\
6 & 0,0000 & 0,0000 & 1,0000 & $7,51 / 7,34$ \\
7 & 0,1667 & 0,1667 & 0,6667 & $8,11 / 8,32$ \\
8 & 0,5000 & 0,5000 & 0,0000 & $6,74 / 6,61$ \\
9 & 0,5000 & 0,0000 & 0,5000 & $7,42 / 7,87$ \\
10 & 1,0000 & 0,0000 & 0,0000 & $6,47 / 6,40$ \\
\hline
\end{tabular}

Na Figura 4 são apresentados a superfície de resposta e o gráfico de curva de níveis correspondentes à função quadrática ajustada à resposta global. Nota-se que, usando-se solução de $\mathrm{HNO}_{3}$ ou $\mathrm{HCl}$ como componentes puros, baixas recuperações do analito são obtidas. Porém, quando a solução de $\mathrm{HCl}$ está associada à solução de $\mathrm{CH}_{3} \mathrm{COOH}$, essa mistura promove as extrações mais eficientes, provavelmente devido às suas propriedades complexantes. Há uma região de misturas binárias entre essas duas últimas soluções que estão na faixa entre 50 e $90 \%$ de ácido acético que permite obter recuperações de cerca de $90 \%$ para os metais estudados. Para $\mathrm{O} \mathrm{Fe}$, as maiores recuperações não ultrapassaram $58 \%$. Então, uma mistura binária composta por $\mathrm{HCl}$ e $\mathrm{CH}_{3} \mathrm{COOH}$ na proporção 1:1 foi escolhida como condição ótima devido ao seu efeito sinérgico na extração.
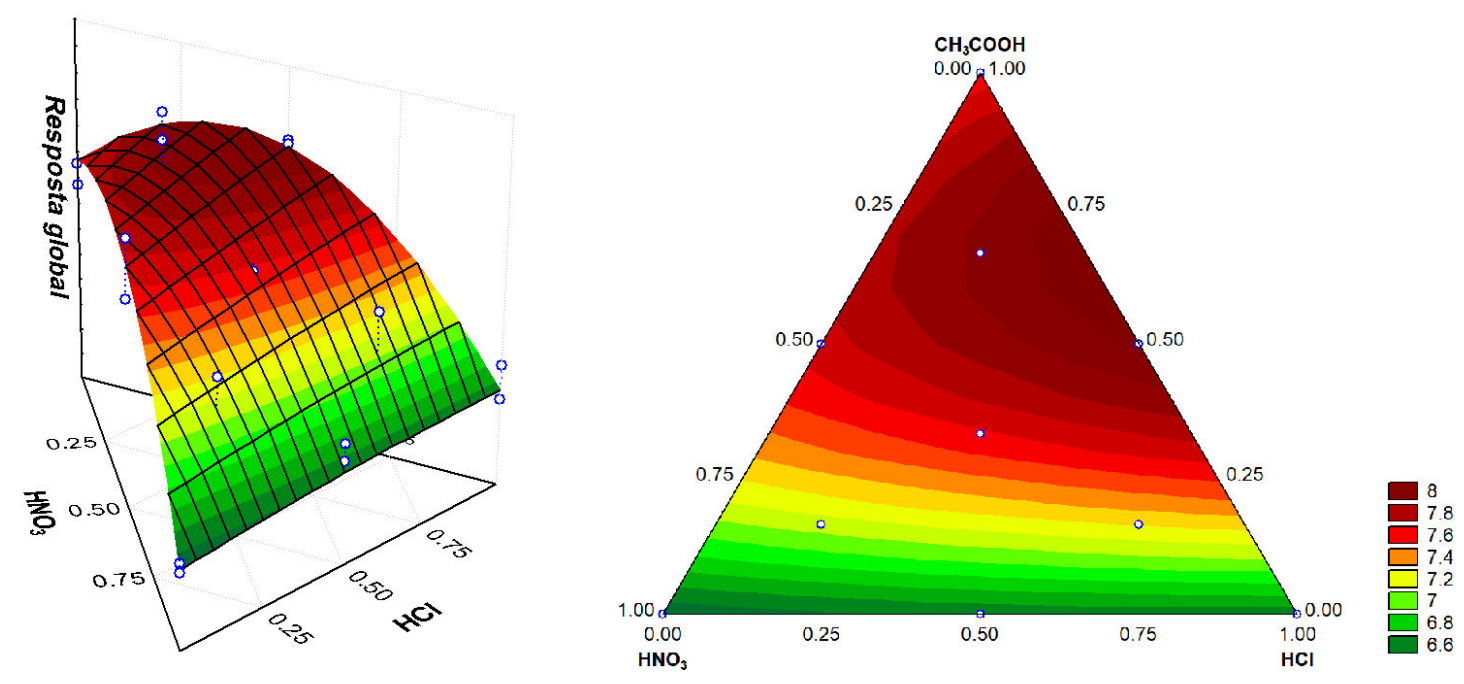

Figura 4. (a) superfície de resposta e (b) gráfico de contorno para a otimização das proporções das soluções extratoras obtidos após ajuste de uma função quadrática. Equação quadrática que gerou a superfície: $R G=6.42\left(\mathrm{HNO}_{3}\right)+6.54(\mathrm{HCl})+7.54\left(\mathrm{CH}_{3} \mathrm{COOH}\right)+0.157$ $\left(\mathrm{HNO}_{3}\right)(\mathrm{HCl})+2.74\left(\mathrm{HNO}_{3}\right)\left(\mathrm{CH}_{3} \mathrm{COOH}\right)+3.91(\mathrm{HCl})\left(\mathrm{CH}_{3} \mathrm{COOH}\right)$ 


\section{Misturas com restrições}

Algumas vezes, por razões práticas, o domínio experimental para um planejamento de misturas deve ser limitado. Isto pode acontecer principalmente devido a dois motivos: (a) a necessidade da presença de todos os componentes para a formação de um determinado material ou para que a mistura apresente o efeito de interesse e (b) a incompatibilidade de algumas proporções entre os componentes na formação da mistura. Sendo assim, surge a necessidade de definir limites inferiores e/ou limites superiores para os componentes de uma mistura. Estes limites estabelecem um novo planejamento que representa uma fração do campo experimental original com coordenadas experimentais diferentes, mas que permitem um estudo eficiente e prático sem cair em situações impossíveis de aplicar o experimento. ${ }^{2,4,6}$

\subsection{Misturas com limites inferiores}

Quando se tem apenas limites inferiores, é possível delimitar uma fração do planejamento original mantendo-se seu formato e propriedades. Isto pode ser feito porque aplicamos $\mathrm{o}$ conceito de pseudocomponentes. ${ }^{9}$

Considere, por exemplo, o planejamento da Figura 6. Este novo triângulo equilátero e os seus vértices podem ser considerados, para efeito de construção da matriz experimental, novos componentes puros. No entanto, estes novos componentes não são na realidade puros e por essa razão eles são chamados de pseudocomponentes.

Os níveis dos componentes originais $\left(x_{i}\right)$ e seus pseudocomponentes $\left(x_{i}^{\prime}\right)$ podem ser relacionados pela equação 19.

$$
x_{i}^{\prime}=\frac{x_{i}-c_{i}}{1-\sum_{i=1}^{k} c_{i}}
$$

onde $c_{i}$ é o limite mínimo para o componente $\mathrm{i}$, observando-se que $\mathrm{c}_{\mathrm{i}} \geq 0$ e $\Sigma \mathrm{c}_{\mathrm{i}}<1$.

$\mathrm{O}$ uso de pseudocomponentes formam um novo planejamento mais adequado a sua aplicação na prática e sem prejuízos no tratamento matemático que seria dado ao planejamento original. ${ }^{4,10}$

\subsection{Misturas com limites inferiores e superiores}

Quando é necessário o estabelecimento de limites inferiores e superiores em um planejamento de misturas, a região delimitada pode não manter mais o formato original (triangular, no caso de três componentes), apresentando uma forma irregular. Então, uma nova abordagem deve ser implementada. Uma forma eficiente de se trabalhar com estas regiões irregulares é incluir no planejamento pontos experimentais que representam vértices extremos e os pontos centróides da região restrita de forma a se obter uniformidade na distribuição desses pontos experimentais. Esta escolha é recomendada uma vez que os erros na estimativa dos coeficientes do modelo matemático ajustado são menores quando os pontos experimentais se distribuem uniformemente pela região de estudo. ${ }^{11,12}$

Um método para se definir os vértices extremos da região experimental delimitada pelas restrições superiores e inferiores baseia-se no algoritmo de McLean e Anderson $^{2}$. Este método requer o estabelecimento de pontos experimentais nos vértices do hiperpoliedro delimitado pelas linhas (ou planos) que representam as restrições para cada componente da mistura. Eles propuseram um algoritmo com as seguintes etapas para se obter as 
coordenadas que, no caso de uma mistura terciária, seria: (1) obter todas as combinações, em par, de níveis inferiores e superiores para os diferentes componentes da mistura e, posteriormente, estabelecer o valor do terceiro componente. Na prática, isto significa pré-selecionar todos os pontos resultantes dos cruzamentos entre as linhas que estabelecem as restrições. Estes pontos pré-selecionados são representados na Figura 5 pelos pontos de $\mathrm{A}$ a $\mathrm{E}$ e de 1 a 6; (2) selecionar apenas os pontos que não violam as restrições estabelecidas e eliminar os demais. Ou seja, os pontos de $A$ a $E$ são eliminados e os de 1 a 6 são selecionados; (3) além dos pontos extremos, pontos centroides são importantes para se ter uma maior confiança no modelo. Eles são obtidos inserindo um ponto equidistante a dois pontos extremos (pontos de 7 a 12) em cada lado da figura plana (neste caso um hexágono) que representa a delimitação do campo experimental e adicionando-se também um ponto central (o ponto 13) que deve estar equidistante de todos os pontos limítrofes do planejamento. ${ }^{2}$

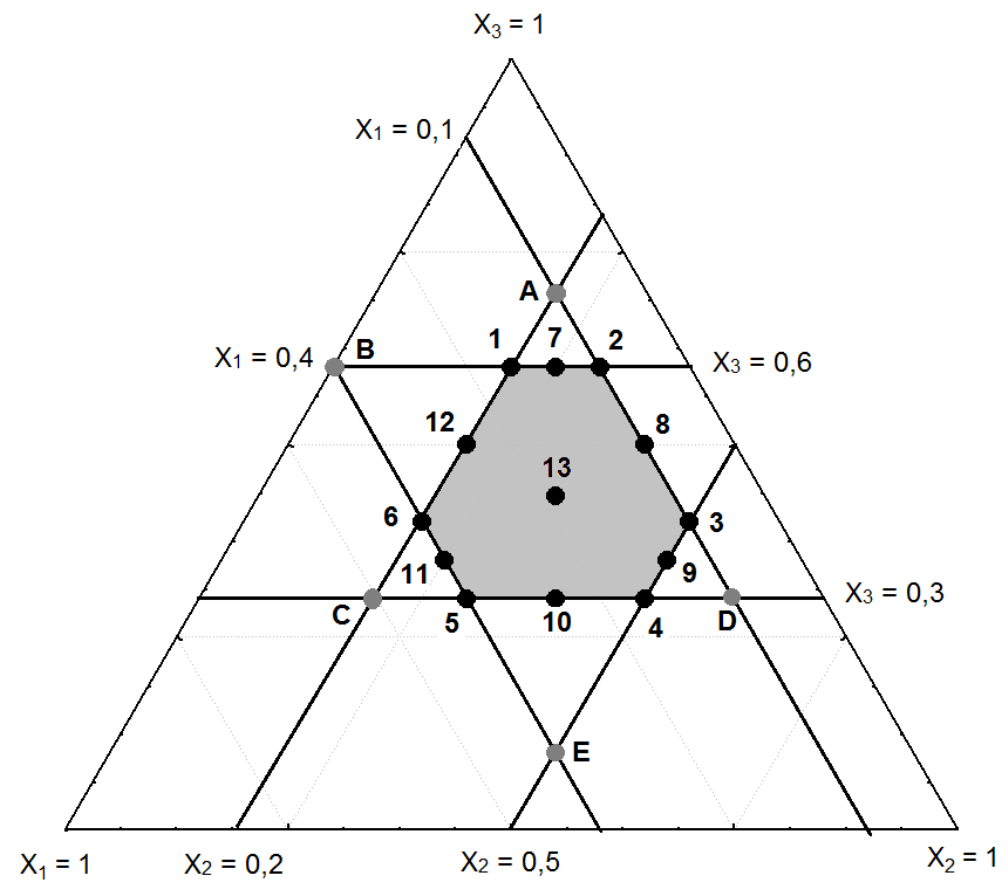

Figura 5. Região experimental de um planejamento de misturas delimitada (hexágono destacado) pelas restrições a $x_{1}\left(0,1 \leq x_{1} \leq 0,4\right) ; x_{2}\left(0,2 \leq x_{2} \leq 0,5\right)$ e $x_{3}\left(0,3 \leq x_{3} \leq 0,6\right)$. Os pontos experimentais de 1 a 13 foram os selecionados e os de $A$ a $E$, eliminados, usando-se $O$ algoritmo de McLean e Anderson ${ }^{2}$

\section{Exemplos de aplicação da MSR na otimização de misturas com restrições}

\section{Exemplo 1}

Bezerra et al. ${ }^{59}$ otimizaram um procedimento para degradação foto- oxidativa usando radiação ultravioleta e $\mathrm{H}_{2} \mathrm{O}_{2}$ para decompor amostras de chorume coletadas em aterros sanitários visando a determinação de metais por FAAS. As proporções de uma mistura formada pelo chorume, pela solução tampão (borato em $\mathrm{pH}=10$ ) e a solução de $\mathrm{H}_{2} \mathrm{O}_{2} 30 \%$, v/v, foram otimizadas usando um planejamento de misturas com restrições. A Tabela 2 mostra a matriz experimental gerada e a Figura 6 apresenta a região delimitada por estas 
restrições. A avaliação da degradação da amostra foi feita observando-se a absorbância em comprimento de onda de $510 \mathrm{~nm}$. Como as misturas com proporções menores da amostra apresentam naturalmente menores absorbâncias a resposta avaliada teve esse efeito corrigido usando-se a razão entre a absorbância e o volume da amostra.

Tabela 2. (a) restrições inferiores e superiores estabelecidas para cada componente da mistura e (b) matriz experimental obtida pela aplicação do planejamento de misturas com restrição.

\begin{tabular}{|c|c|c|c|c|c|c|}
\hline \multicolumn{7}{|c|}{ (a) Restrições } \\
\hline \multicolumn{3}{|c|}{ Variável de mistura } & \multicolumn{2}{|c|}{ Restrições inferiores } & \multicolumn{2}{|c|}{ Restrições superiores } \\
\hline \multicolumn{3}{|c|}{ Volume de chorume $(\mathrm{mL})$} & \multicolumn{2}{|l|}{5} & \multicolumn{2}{|r|}{8} \\
\hline \multicolumn{3}{|c|}{ Volume de $\mathrm{H}_{2} \mathrm{O}_{2}(\mathrm{~mL})$} & \multicolumn{2}{|l|}{1} & \multicolumn{2}{|r|}{4} \\
\hline \multicolumn{3}{|c|}{ Volume de solução tampão (mL) } & \multicolumn{2}{|l|}{1} & \multicolumn{2}{|r|}{4} \\
\hline \multicolumn{7}{|c|}{ (b) Matriz experimental e respostas } \\
\hline Exp & $\begin{array}{c}\text { Chorume } \\
(\mathrm{mL})\end{array}$ & $\mathrm{H}_{2} \mathrm{O}_{2}(\mathrm{~mL})$ & Tampão (mL) & \multicolumn{2}{|c|}{ Abs } & $\begin{array}{l}\text { Abs/Volume da } \\
\text { amostra }\end{array}$ \\
\hline 1 & 8,0 & 1,0 & 1,0 & \multicolumn{2}{|c|}{$0,664 / 0,649$} & $0,0830 / 0,0811$ \\
\hline 2 & 5,0 & 4,0 & 1,0 & \multicolumn{2}{|c|}{$0,233 / 0,214$} & $0,0466 / 0,0428$ \\
\hline 3 & 5,0 & 1,0 & 4,0 & \multicolumn{2}{|c|}{$0,194 / 0,212$} & $0,0388 / 0,0424$ \\
\hline 4 & 5,0 & 2,5 & 2,5 & \multicolumn{2}{|c|}{$0,186 / 0,210$} & $0,0372 / 0,0420$ \\
\hline 5 & 6,5 & 1,0 & 2,5 & \multicolumn{2}{|c|}{$0,685 / 0,725$} & $0,1054 / 0,1115$ \\
\hline 6 & 6,5 & 2,5 & 1,0 & \multicolumn{2}{|c|}{$0,356 / 0,373$} & $0,0548 / 0,0574$ \\
\hline 7 & 6,0 & 2,0 & 2,0 & \multicolumn{2}{|c|}{$0,381 / 0,342$} & $0,0635 / 0,0570$ \\
\hline 8 & 5,5 & 1,5 & 3,0 & \multicolumn{2}{|c|}{$0,392 / 0,327$} & $0,0713 / 0,0595$ \\
\hline 9 & 5,5 & 3,0 & 1,5 & \multicolumn{2}{|c|}{$0,284 / 0,249$} & $0,0516 / 0,0453$ \\
\hline 10 & 7,0 & 1,5 & 1,5 & \multicolumn{2}{|c|}{$0,755 / 0,629$} & $0,1079 / 0,0899$ \\
\hline
\end{tabular}

A superfície obtida apresentou um ponto de sela e a análise de variância mostrou que o modelo quadrático ajustado não apresenta falta de ajuste $(p=0,4488>0,05)$. A análise da superfície mostra que uma mistura contendo $65 \%$ da amostra, $25 \%$ de $\mathrm{H}_{2} \mathrm{O}_{2}$ e
$10 \%$ da solução do tampão em $\mathrm{pH} 10$ permitem uma degradação eficiente do chorume $e$, consequentemente, a determinação de metais sem o efeito de matriz observado na amostra original. 


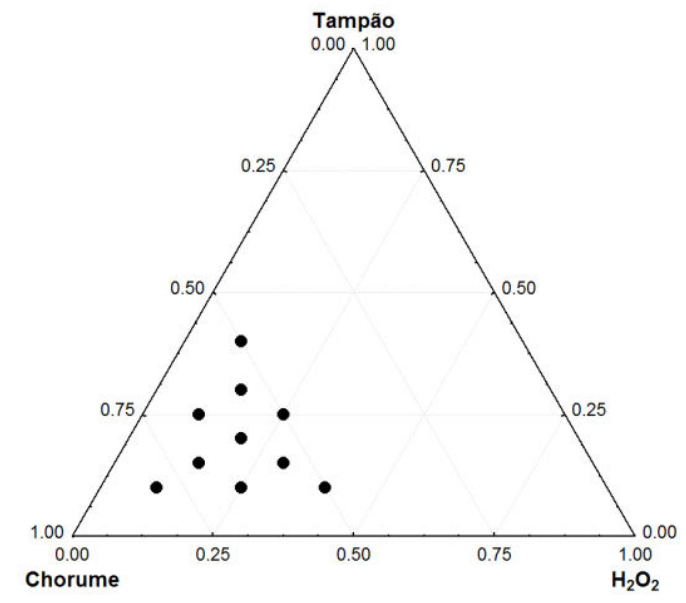

Figura 6. Região experimental para otimização da composição de diferentes misturas após a aplicação de restrições na otimização da digestão de amostras de chorume por irradiação ultravioleta

\section{Exemplo 2}

Cano et al. ${ }^{60}$ utilizaram um planejamento de misturas para otimizar a composição da fase móvel na separação de carboidratos em mel usando cromatografia líquida de alta eficiência com eluição isocrática. Desta forma, um planejamento centróide simplex com pontos axiais em uma representação de pseudocomponentes foi gerada a partir dos componentes puros: acetonitrila, água e acetato de etila. Os pseudocomponentes foram dados pelos pontos experimentais $x_{1}$ $(50: 10: 40), x_{2}(70: 10: 20)$ e $x_{3}(60: 14: 26)$ para as proporções de acetonitrila, água e acetato de etila, respectivamente. Combinações binárias e ternárias adicionais destes pseudocomponentes foram preparadas conforme os experimentos descritos na Tabela 3. Um dos pontos axiais do planejamento original $(1 / 6,1 / 6$ e $2 / 3)$ não foi realizado, pois um teste prévio com esta mistura ternária de solventes sugeriu a restrição desta proporção para evitar problemas com miscibilidade.

Tabela 3. Composição da fase móvel usada segundo os experimentos do planejamento de misturas

\begin{tabular}{|c|c|c|c|c|c|c|c|}
\hline \multirow[b]{2}{*}{ Exp. } & \multirow[b]{2}{*}{ Réplica } & \multicolumn{3}{|c|}{ Composição em pseudocomponentes } & \multicolumn{3}{|c|}{ Composição real (\%) } \\
\hline & & 1 & 2 & 3 & Acetonitrila & Água & $\begin{array}{l}\text { Acetato } \\
\text { de etila }\end{array}$ \\
\hline 1 & 2 & 1 & 0 & 0 & 50 & 10 & 40 \\
\hline 2 & 2 & 0 & 1 & 0 & 70 & 10 & 20 \\
\hline 3 & 2 & 0 & 0 & 1 & 60 & 14 & 26 \\
\hline 4 & 2 & $1 / 2$ & $1 / 2$ & 0 & 60 & 10 & 30 \\
\hline 5 & 2 & $1 / 2$ & 0 & $1 / 2$ & 55 & 12 & 33 \\
\hline 6 & 2 & 0 & $1 / 2$ & $1 / 2$ & 65 & 12 & 23 \\
\hline 7 & 6 & $1 / 3$ & $1 / 3$ & $1 / 3$ & 60 & 11.3 & 28.7 \\
\hline 8 & 1 & $2 / 3$ & $1 / 6$ & $1 / 6$ & 55 & 10.4 & 34.6 \\
\hline 9 & 1 & $1 / 6$ & $2 / 3$ & $1 / 6$ & 65 & 11.7 & 23.3 \\
\hline
\end{tabular}

Duas funções de respostas base nos fatores de retenção de picos cromatográficas foram avaliadas, ПRs (com adjacentes) e COF (chromatographic 
optimization function), ajustando-se modelos como o linear, o quadrático e o cúbico especial nos resultados obtidos pela variação dos proporções dos pseudocomponentes. Estas funções de resposta são consideradas adequadas para se avaliar a qualidade da separação dos picos para misturas multicomponentes, pois fornece um único valor numérico para a descrição do cromatograma. Análise de variância foi aplicada aos dados para avaliar a falta de ajuste e a significância estatística dos modelos. O modelo cúbico especial foi o que melhor se ajustou aos dados gerados pelas duas respostas cromatográficas, não apresentando falta de ajuste e, portanto, as duas podem ser usadas na otimização da separação dos carboidratos. O gráfico de valores preditos versus valores observados (não mostrado) confirma que existe uma boa correlação entre os valores preditos pela função matemática adotada e os valores observados experimentalmente.

O modelo matemático cúbico especial ajustado aos dados da COF, que origina a superfície de resposta analisada, é mostrado na equação 20.

$$
\begin{aligned}
& \text { COF1.2 }=+0.012 X_{1}-0.086 X_{2}-0.424 X_{3}+0.159 X_{1} X_{2}+0.372 X_{1} X_{3}+0.154 X_{2} X_{3}-1.159 X_{1} X_{2} X_{3} \\
& \begin{array}{lllllll}
( \pm 0.005) & ( \pm 0.005) & ( \pm 0.005) & ( \pm 0.023) & ( \pm 0.023) & ( \pm 0.023) & ( \pm 0.126)
\end{array}
\end{aligned}
$$

Nessa equação, os erros padrão são apresentados entre parênteses abaixo de seus respectivos coeficientes. Todos os termos binários e terciários se mostraram significativos em um nível de confiança de $95 \%$, bem como os coeficientes lineares.

Após análise dos dados, as melhores proporções encontradas para os componentes da fase móvel foram 50:10:40 (v:v:v) para acetonitrila, água e acetato de etila, respectivamente.

\section{Planejamento de misturas na otimização de procedimentos analíticos}

Planejamentos de misturas associados à metodologia de superfície de respostas vêm sendo ainda timidamente aplicados na otimização de alguma etapa de métodos analíticos visando a obtenção dos melhores parâmetros de mérito para determinar uma substância. A Tabela 4 apresenta alguns trabalhos recentemente publicados nos quais se utiliza alguma modalidade de planejamento de mistura. A maior parte dos trabalhos se referem à otimização da fase líquida na cromatografia líquida de alta eficiência (CLAE) em eluição isocrática seguida por aplicações na otimização de tratamento de amostras para posterior análise por espectrometria atômica.

\section{Conclusões}

Metodologia de superfície de resposta é uma ferramenta eficaz na otimização de variáveis de misturas e no desenvolvimento de métodos analíticos devido às suas diversas vantagens como a economia experimental e o estudo racional dos sistemas. Vários modelos matemáticos podem ser ajustados aos dados gerados a partir de um planejamento de misturas de forma a garantir a melhor descrição do comportamento do sistema. A possibilidade de trabalhar com restrições experimentais também demonstra a grande versatilidade destes tipos de planejamentos. Embora os planejamentos de misturas ainda sejam pouco usados em química, as suas potencialidades na otimização de procedimentos são muito promissoras. 
Tabela 4. Algumas aplicações recentes de planejamentos de mistura na otimização de métodos analíticos

\begin{tabular}{|c|c|c|c|c|}
\hline Analitos ou resposta & Amostras & Técnica analítica & Objetivos da otimização com planejamento de misturas & Ref. \\
\hline $\begin{array}{l}\text { Matéria bruta total e as } \\
\text { frações: neutra, básica, } \\
\text { residual e de fibras }\end{array}$ & $\begin{array}{l}\text { Folhas de Mikania } \\
\text { laevigata Sch. Bip. }\end{array}$ & $\begin{array}{l}\text { Medidas gravimétricas } \\
\text { dos extratos após } \\
\text { evaporação do solvente } \\
\text { extrator }\end{array}$ & $\begin{array}{l}\text { Investigar os efeitos sinérgicos dos solventes etanol, acetato de } \\
\text { etila, diclorometano, acetona e clorofórmio e suas misturas em } \\
\text { diferentes proporções na extração da matéria bruta total e } \\
\text { diferentes frações a partir de folhas vegetais }\end{array}$ & 13 \\
\hline $\begin{array}{l}\text { Glicerol, carbamato de } \\
\text { glicerol e uréia }\end{array}$ & Soluções com os analitos & $\begin{array}{l}\text { Cromatografia líquida } \\
\text { de alta eficiência }\end{array}$ & $\begin{array}{l}\text { Modelar, com ajuda da função de desejabilidade, os fatores de } \\
\text { retenção em função da fase móvel composta por acetonitrila, } \\
\text { água e metanol em três colunas cromatográficas diferentes }\end{array}$ & 14 \\
\hline $\begin{array}{l}\text { Remoção do As }(V) \text { e } \\
\text { resistência mecânica }\end{array}$ & Águas & ICP OES & $\begin{array}{l}\text { Determinar a proporção ótima da mistura de argila, amido de } \\
\text { trigo e } \mathrm{Fe}_{2} \mathrm{O}_{3} \text { na fabricação de uma cerâmica que proporcione a } \\
\text { melhor eficiência de remoção do As (V) e melhor força } \\
\text { mecânica do material }\end{array}$ & 15 \\
\hline Pesticidas & Tomates & $\begin{array}{l}\text { Cromatografia gasosa } \\
\text { com detector de } \\
\text { captura de elétrons }\end{array}$ & $\begin{array}{l}\text { Estabelecer as melhores proporções de acetonitrila, água e } \\
\text { acetato de etila em uma mistura para extrair eficientemente } \\
\text { quatro pesticidas em amostras de tomate }\end{array}$ & 16 \\
\hline Proteínas & $\begin{array}{l}\text { Solução sintética } \\
\text { composta por mistura de } \\
\text { três proteínas }\end{array}$ & $\begin{array}{l}\text { Cromatografia líquida } \\
\text { capilar de alta eficiência }\end{array}$ & $\begin{array}{l}\text { Estudar as proporções das substâncias que compõem a mistura } \\
\text { de polimerização (monômero, regente de ligação cruzada e } \\
\text { porogênio) na fabricação da fase estacionária monolítica e seu } \\
\text { efeito em duas respostas cromatográficas: a resolução média } \\
\text { entre as três proteínas e o tempo de retenção do último pico }\end{array}$ & 17 \\
\hline $\begin{array}{l}\mathrm{Al}, \mathrm{As}, \mathrm{Ba}, \mathrm{Ca}, \mathrm{Cd}, \mathrm{Co} \\
\mathrm{Cu}, \mathrm{Fe}, \mathrm{Mg}, \mathrm{Mn}, \mathrm{V} \text { e } \mathrm{Zn}\end{array}$ & Tecidos de ostras & ICP OES & $\begin{array}{l}\text { Estabelecer as proporções de } \mathrm{HNO}_{3}, \mathrm{HCl} \text { e } \mathrm{H}_{2} \mathrm{O}_{2} \text { que favoreça a } \\
\text { digestão eficiente do material biológico com boas recuperações } \\
\text { dos metais estudados tendo-se como base um material de } \\
\text { referência certificado }\end{array}$ & 18 \\
\hline $\begin{array}{l}\text { Pesticidas e compostos } \\
\text { neutros }\end{array}$ & $\begin{array}{l}\text { Solução sintética das } \\
\text { substâncias estudadas }\end{array}$ & $\begin{array}{l}\text { Cromatografia líquida } \\
\text { de alta eficiência }\end{array}$ & $\begin{array}{l}\text { Otimização das proporções dos componentes da fase móvel } \\
\text { compostas por soluções aquosas de acetonitrila, metanol e }\end{array}$ & 19 \\
\hline
\end{tabular}




\begin{tabular}{|c|c|c|c|c|}
\hline & & & $\begin{array}{l}\text { tetrahidrofurano tendo-se como resposta o fator de retenção, a } \\
\text { resolução e a retenção relativa. }\end{array}$ & \\
\hline $\begin{array}{l}\text { Al, } \mathrm{As}, \mathrm{Be}, \mathrm{Bi}, \mathrm{Ca}, \mathrm{Cd} \\
\mathrm{Co}, \mathrm{Cr}, \mathrm{Cu}, \mathrm{Fe}, \mathrm{Hg}, \mathrm{K} \\
\mathrm{Mg}, \mathrm{Mn}, \mathrm{Mo}, \mathrm{Na}, \mathrm{Ni}, \mathrm{Pb} \\
\text { Sb, } \mathrm{Si}, \mathrm{Sn}, \mathrm{Tl} \text { e Zn }\end{array}$ & $\begin{array}{l}\text { Materiais têxteis de } \\
\text { algodão }\end{array}$ & ICP OES & $\begin{array}{l}\text { Estabelecer as melhores proporções entre as soluções de } \mathrm{HNO}_{3} \text {, } \\
\mathrm{HCl} \text { e água na extração assistida por ultrassom de } 23 \text { elementos } \\
\text { em material têxtil de algodão }\end{array}$ & 20 \\
\hline Corantes catiônicos & $\begin{array}{l}\text { Fibras acrílicas de } \\
\text { interesse forense }\end{array}$ & $\begin{array}{l}\text { Eletroforese capilar e } \\
\text { espectrometria de } \\
\text { massas }\end{array}$ & $\begin{array}{l}\text { Explorar os efeitos das proporções de três componentes de } \\
\text { uma mistura de solventes (água, solução de ácido fórmico e } \\
\text { solução de ácido acético) na microextração automatizada de } \\
\text { corantes catiônicos a partir de fibras acrílicas }\end{array}$ & 21 \\
\hline $\begin{array}{l}\text { Matéria bruta total e as } \\
\text { frações: neutra, básica, } \\
\text { residual e de fibras }\end{array}$ & $\begin{array}{l}\text { Folhas de Erythrina } \\
\text { speciosa Andrews }\end{array}$ & $\begin{array}{l}\text { Medidas gravimétricas } \\
\text { dos extratos após } \\
\text { evaporação do solvente } \\
\text { extrator }\end{array}$ & $\begin{array}{l}\text { Investigar os efeitos dos solventes etanol, diclorometano, } \\
\text { hexano e acetona puros e em diferentes proporções em uma } \\
\text { mistura na extração da matéria bruta total e diferentes frações } \\
\text { a partir de folhas vegetais }\end{array}$ & 22 \\
\hline $\begin{array}{l}\text { Fingerprints } \\
\text { cromatográficos }\end{array}$ & $\begin{array}{l}\text { Espécies vegetais do } \\
\text { gênero Bauhinia }\end{array}$ & $\begin{array}{l}\text { Cromatografia líquida } \\
\text { de alta eficiência }\end{array}$ & $\begin{array}{l}\text { Estabelecimento das proporções ótimas dos solventes etil } \\
\text { acetato, diclorometano e etanol para extração de substâncias } \\
\text { químicas de espécies vegetais do gênero Bauhinia e otimização } \\
\text { da fase móvel (metanol, acetonitrila e água) para separação } \\
\text { cromatográfica das substâncias extraídas }\end{array}$ & 23 \\
\hline $\begin{array}{l}\text { Fingerprints } \\
\text { cromatográficos }\end{array}$ & $\begin{array}{l}\text { Extratos de Bauhinia } \\
\text { variegata } L .\end{array}$ & $\begin{array}{l}\text { Cromatografia líquida } \\
\text { de alta eficiência }\end{array}$ & $\begin{array}{l}\text { Otimizar as proporções dos solventes usados como meio } \\
\text { extrator (acetona, etanol e diclorometano) e dos solventes } \\
\text { usados como fase móvel (metanol acetonitrla e água) na } \\
\text { melhoria da qualidade dos fingerprints cromatográficos }\end{array}$ & 24 \\
\hline $\begin{array}{l}\text { Escores da } \\
\text { transformação Varimax } \\
\text { de cromatogramas }\end{array}$ & $\begin{array}{l}\text { Folhas de Erythrina } \\
\text { speciosa Andrews }\end{array}$ & $\begin{array}{l}\text { Cromatografia líquida } \\
\text { de alta eficiência }\end{array}$ & $\begin{array}{l}\text { Estabelecimento das proporções ótimas dos solventes } \\
\text { diclorometano, hexano, etanol e acetona para extração de } \\
\text { substâncias químicas da espécies Erythrina speciosa Andrews }\end{array}$ & 25 \\
\hline Tempos de retenção & Erythrina & Cromatografia & Otimizar as proporções de diclorometano, etanol, hexano e & 26 \\
\hline
\end{tabular}




\begin{tabular}{|c|c|c|c|c|}
\hline $\begin{array}{l}\text { convertidos em } \\
\text { componentes principais }\end{array}$ & speciosa Andrews & de alta eficiência & $\begin{array}{l}\text { acetona na extração de três grupos de compostos com } \\
\text { propriedades similares }\end{array}$ & \\
\hline $\begin{array}{l}\text { Fingerprints } \\
\text { cromatográficos }\end{array}$ & Folhas de chá verde & $\begin{array}{l}\text { Cromatografia líquida } \\
\text { de alta eficiência }\end{array}$ & $\begin{array}{l}\text { Estudar a influencia de diferentes solventes na extração } \\
\text { (acetato de etila, etanol e diclorometano) e na composição da } \\
\text { fase móvel (metanol, acetonitrila e água) na obtenção de } \\
\text { fingerprints de boa qualidade }\end{array}$ & 27 \\
\hline $\begin{array}{l}\text { Fingerprints } \\
\text { cromatográficos }\end{array}$ & $\begin{array}{lrr}\text { Planta da } & \text { espécie } \\
\text { Baccharis } & \text { milleflora } \\
\text { (Less.) DC } & \end{array}$ & $\begin{array}{l}\text { Cromatografia líquida } \\
\text { de alta eficiência }\end{array}$ & $\begin{array}{l}\text { Estabelecimento das proporções ótimas de solventes extratores } \\
\text { (etanol, acetato de etila e diclorometano) e da composição da } \\
\text { fase móvel (metanol, acetonitrila e água) objetivando melhorar } \\
\text { a qualidade dos fingerprints }\end{array}$ & 28 \\
\hline $\begin{array}{l}\text { Eprosartan, } \\
\text { Telmisartan, Irbesartan } \\
\text { e Valsartan }\end{array}$ & Urina humana & $\begin{array}{l}\text { Cromatografia líquida } \\
\text { de alta eficiência }\end{array}$ & $\begin{array}{l}\text { Desenvolver um procedimento com base em extração em fase } \\
\text { sólida otimizando as proporções da mistura de eluição } \\
\text { (metanol, acetonitrila, etanol e acetona) de forma a se ter as } \\
\text { melhores recuperações dos analitos }\end{array}$ & 29 \\
\hline $\begin{array}{l}\text { Fingerprints } \\
\text { cromatográficos }\end{array}$ & $\begin{array}{l}\text { Folhas de Camellia } \\
\text { sinensis }\end{array}$ & $\begin{array}{l}\text { Cromatografia líquida } \\
\text { de alta eficiência }\end{array}$ & $\begin{array}{l}\text { Otimizar simultaneamente dois sistemas de misturas: um para } \\
\text { extração de substâncias usando os solventes acetato de etila, } \\
\text { etanol e diclorometano e outro formado pelos componentes da } \\
\text { fase móvel (metanol, acetonitrila e água) na obtenção de } \\
\text { fingerprints }\end{array}$ & 30 \\
\hline $\begin{array}{l}\text { Droga antiflamatória } \\
\text { (ketorolac) } \\
\text { substâncias } \\
\text { relacionadas }\end{array}$ & $\begin{array}{l}\text { Comprimidos } \\
\text { analgésicos }\end{array}$ & $\begin{array}{l}\text { Cromatografia } \\
\text { eletrocinética capilar } \\
\text { em microemulsão }\end{array}$ & $\begin{array}{l}\text { Utilizar planejamento de misturas e função de desejabilidade } \\
\text { para otimizar os componentes da microemulsão (solução } \\
\text { tampão, surfactante e n-heptano) considerando o tempo de } \\
\text { análise e resolução como respostas }\end{array}$ & 31 \\
\hline Naftodiantronas & $\begin{array}{l}\text { Extratos de erva de São } \\
\text { João } \\
\text { perforatum) }\end{array}$ & $\begin{array}{l}\text { Cromatografia líquida } \\
\text { de alta eficiência }\end{array}$ & $\begin{array}{l}\text { Usar planejamento de misturas e função de desejabilidade na } \\
\text { otimização da proporção de metanol, solução tampão e acetato } \\
\text { de etila na fase extratora }\end{array}$ & 32 \\
\hline $\begin{array}{lr}\text { Drogas } & \text { psicotrópicas e } \\
\text { seus } & \text { principais }\end{array}$ & Medicamentos & Cromatografia & $\begin{array}{l}\text { Usar planejamento de misturas com restrições da região } \\
\text { experimental associado à função de desejabilidade na }\end{array}$ & 33 \\
\hline
\end{tabular}




\begin{tabular}{|c|c|c|c|c|}
\hline metabólitos & & de alta eficiência & $\begin{array}{l}\text { otimização da composição da fase móvel (tampão, acetonitrila } \\
\text { e metanol) juntamente com algumas variáveis de método (pH e } \\
\text { concentração do tampão) }\end{array}$ & \\
\hline Sn e Hg & Sedimentos & $\begin{array}{l}\text { Espectrometria de } \\
\text { absorção atômica com } \\
\text { geração de hidretos por } \\
\text { sistema de injeção em } \\
\text { fluxo }\end{array}$ & $\begin{array}{l}\text { Otimizar as proporções de } \mathrm{HNO}_{3}, \mathrm{HCl} \text { e } \mathrm{H}_{2} \mathrm{O} \text { na digestão } \\
\text { assistida por micro-ondas de amostras de sedimentos }\end{array}$ & 34 \\
\hline Carbamazepina & Soro humano & $\begin{array}{l}\text { Cromatografia líquida } \\
\text { de alta eficiência }\end{array}$ & $\begin{array}{l}\text { Investigar a influência das proporções dos solventes (benzeno, } \\
\text { tolueno e 1-pentanol) sobre a recuperação do analito a partir } \\
\text { da amostra real }\end{array}$ & 36 \\
\hline Nonilfenóis e ésteres & Sedimentos & $\begin{array}{lr}\text { Cromatografia } & \text { gasosa } \\
\text { acoplada à } \\
\text { espectrometria } \\
\text { massas e cromatografia } \\
\text { líquida de alta eficiência }\end{array}$ & $\begin{array}{l}\text { Usar planejamento de misturas combinado com planejamento } \\
\text { D-ótimo para estabelecer os melhores valores para a pressão } \\
\text { do sistema de digestão, o tempo de extração e a composição do } \\
\text { solvente extrator (metanol, acetona e n-hexano) }\end{array}$ & 37 \\
\hline Glucose oxidase & Planta Aspergillus niger & $\begin{array}{l}\text { Espectrofotometria no } \\
\text { visível }\end{array}$ & $\begin{array}{l}\text { Usar planejamento fatorial fracionário de dois níveis combinado } \\
\text { com planejamento de misturas na otimização da extração } \\
\text { líquido-líquido de enzima usando os solventes isooctano, } \\
\text { hexanol e butanol. }\end{array}$ & 38 \\
\hline $\mathrm{Ni}$ & $\begin{array}{l}\text { Soluções sintéticas do } \\
\text { metal }\end{array}$ & $\begin{array}{l}\text { Voltametria de } \\
\text { redissolução anódica }\end{array}$ & $\begin{array}{l}\text { Usar a otimização do sistema de solventes composto por } \mathrm{N}, \mathrm{N}- \\
\text { dimetilformamida, água e etanol como exemplo didático da } \\
\text { aplicação de um planejamento de misturas com restrições }\end{array}$ & 39 \\
\hline $\mathrm{Pb}$ & Soluções sintéticas & Voltametria & Aplicar planejamento do tipo split-plot na otimização de & 40 \\
\hline
\end{tabular}




\begin{tabular}{|c|c|c|c|c|}
\hline & metal & redissolução anódica & $\begin{array}{l}\text { variáveis de processos e variáveis de misturas ( } \mathrm{N}, \mathrm{N}- \\
\text { dimetilformamida, água e etanol) na melhoria da detecção do } \\
\text { chumbo }\end{array}$ & \\
\hline Licopeno & $\begin{array}{l}\text { Tomates e produtos } \\
\text { derivados de tomate }\end{array}$ & $\begin{array}{l}\text { Espectrofotometria no } \\
\text { visível }\end{array}$ & $\begin{array}{l}\text { Investigar as melhores proporções dos solventes (etanol, } \\
\text { hexano e acetona) na extração do licopeno }\end{array}$ & 41 \\
\hline $\begin{array}{l}\text { L-fenilalanina, L-tirosina } \\
\text { e L-triptofano }\end{array}$ & $\begin{array}{l}\text { Soluções sintéticas dos } \\
\text { aminoácidos }\end{array}$ & $\begin{array}{l}\text { Cromatografia líquida } \\
\text { de alta eficiência }\end{array}$ & $\begin{array}{l}\text { Investigar e modelar a separação dos aminoácidos estudados } \\
\text { em função das proporções das soluções de } \mathrm{H}_{3} \mathrm{PO}_{4}, \mathrm{NaH}_{2} \mathrm{PO}_{4} \text { e } \\
\mathrm{NaClO}_{4} \text { na composição da fase móvel }\end{array}$ & 42 \\
\hline $\mathrm{Cu}$ & Amostras de óleos & $\begin{array}{l}\text { Voltametria de } \\
\text { redissolução catódica }\end{array}$ & $\begin{array}{l}\text { Otimizar um sensor voltamétrico por redissolução usando um } \\
\text { planejamento de misturas aliado às abordagens de rede neural } \\
\text { artificial e algoritmo genético encontrando os melhores valores } \\
\text { para pH e para as proporções dos componentes da membrana } \\
\text { (nanotubos de carbono, pó de grafite e iodoquinol) }\end{array}$ & 44 \\
\hline $\begin{array}{l}\text { Compostos com } \\
\text { atividade antioxidante } \\
\text { e polifenóis totais }\end{array}$ & $\begin{array}{l}\text { Extrato bruto de cascas } \\
\text { de Trichilia catigua }\end{array}$ & $\begin{array}{l}\text { Espectrofotometria e } \\
\text { Cromatografia líquida } \\
\text { de alta eficiência }\end{array}$ & $\begin{array}{l}\text { Investigar os efeitos de diferentes solventes (água, metanol, } \\
\text { acetona e etanol) e suas misturas na extração das substâncias } \\
\text { de interesse }\end{array}$ & 46 \\
\hline $\begin{array}{lr}\text { Compostos } & \text { fenólicos } \\
\text { totais, } & \text { atividades }\end{array}$ & Sementes de Caesalpinia & Espectrofotometria & Avaliar as proporções de $\mathrm{CO}_{2}$, etanol e água na extração por & 47 \\
\hline
\end{tabular}

Rev. Virtual Quim. |Vol 10| | No. 2| |393-420| 


\begin{tabular}{|c|c|c|c|c|}
\hline $\begin{array}{ll}\text { antioxidante } & \text { e } \\
\text { antiflamatória } & \end{array}$ & spinosa & & solvente pressurizada das substâncias de interesse & \\
\hline $\begin{array}{l}\text { Atividades } \\
\text { antioxidantes de três } \\
\text { catequinas }\end{array}$ & $\begin{array}{l}\text { Folhas de Camellia } \\
\text { sinensis } L \text {. }\end{array}$ & $\begin{array}{l}\text { Cromatografia líquida } \\
\text { de alta eficiência }\end{array}$ & $\begin{array}{l}\text { Otimização das proporções dos solventes (etanol, acetato de } \\
\text { etila, diclorometano e clorofórmio) da mistura extratora e dos } \\
\text { componentes (acetonitrila, água e etanol) da fase móvel }\end{array}$ & 48 \\
\hline $\begin{array}{ll}\text { Fingerprints } & \text { de } \\
\text { metabólitos } & \end{array}$ & $\begin{array}{l}\text { Extrato bruto de folhas de } \\
\text { Erythrina } \quad \text { speciosa } \\
\text { Andrews }\end{array}$ & $\begin{array}{l}\text { Cromatografia líquida } \\
\text { de alta eficiência }\end{array}$ & $\begin{array}{l}\text { Estudar o efeito de quatro solventes (hexano, diclorometano, } \\
\text { acetato de etila e metanol) e suas misturas na obtenção de } \\
\text { fingerprints de metabólitos }\end{array}$ & 49 \\
\hline $\begin{array}{l}\text { Ésteres ftalato e di(2- } \\
\text { etil-hexil)-adipato }\end{array}$ & $\begin{array}{l}\text { Água mineral, suco de } \\
\text { limão, soda limonada, } \\
\text { sucos, vinagre, massas e } \\
\text { iorgute armazenados em } \\
\text { embalagens plásticas }\end{array}$ & Cromatografia gasosa & $\begin{array}{l}\text { Estudar a composição de uma mistura ternária (diclorometano, } \\
\text { clorofórmio e tetracloreto de carbono) tendo-se } \\
\text { dimetilformamida como dispersante na microextração líquido- } \\
\text { líquido eficiente das substâncias de interesse }\end{array}$ & 50 \\
\hline $\mathrm{Cd}, \mathrm{Cu}$ and $\mathrm{Ni}$ & Sedimentos & ICP OES & $\begin{array}{l}\text { Otimizar as proporções de soluções que promovem a extração } \\
\text { simultânea dos três metais no ponto nuvem do surfactante } \\
\text { Triton X-114 }\end{array}$ & 51 \\
\hline $\begin{array}{l}\mathrm{Ca}, \mathrm{Cu}, \mathrm{Fe}, \mathrm{K}, \mathrm{Mg}, \mathrm{Mn} \text {, } \\
\mathrm{Na}, \mathrm{Sr} \text { and } \mathrm{Zn}\end{array}$ & Folhas vegetais & ICP OES & $\begin{array}{l}\text { Encontrar condição ótima para digestão assistida por energia de } \\
\text { micro-ondas que satisfaça simultaneamente a obtenção de um } \\
\text { baixo teor de carbono residual e uma baixa acidez final para os } \\
\text { digeridos }\end{array}$ & 52 \\
\hline $\mathrm{Sb}$ & Cabelos humanos & HG-AFS & $\begin{array}{l}\text { Otimizar as proporções de agentes (água, } \mathrm{HNO}_{3} \text { e } \mathrm{HCl} \text { ) que } \\
\text { promovem a digestão de amostras de cabelo em um sistema de } \\
\text { micro-ondas com frascos pressurizados visando obter alta } \\
\text { intensidade de fluorescência }\end{array}$ & 53 \\
\hline $\begin{array}{l}\text { Ácidos clorogênicos, } \\
\text { cafeína e trigonelina }\end{array}$ & Café (Coffea arábica) & $\begin{array}{l}\text { Cromatografia líquida } \\
\text { de alta eficiência com } \\
\text { detector de arranjo de }\end{array}$ & $\begin{array}{l}\text { Estudar os efeitos de quatro solventes (etanol, acetato de etila, } \\
\text { diclorometano e hexano) e sua misturas na extração de ácidos } \\
\text { clorogênicos, cafeína e trigonelina a partir de extratos crus de }\end{array}$ & 54 \\
\hline
\end{tabular}




\begin{tabular}{|c|c|c|c|c|}
\hline & & fotodíodos & quatro cultivares de cafés & \\
\hline Fenólicos totais & Bagaço de caju & Espectrofotometria & $\begin{array}{l}\text { Definir as proporções ótimas dos solventes (etanol, acetona e } \\
\text { água) que permita a máxima extração de fenóis. }\end{array}$ & 55 \\
\hline $\begin{array}{l}\mathrm{Ba}, \mathrm{Ca}, \mathrm{Cu}, \mathrm{Fe}, \mathrm{K}, \mathrm{Mg}, \\
\mathrm{Mn}, \mathrm{Sr} \text { e } \mathrm{Zn}\end{array}$ & Feijões & ICP OES & $\begin{array}{l}\text { Estudar soluções de } \mathrm{HNO}_{3}, \mathrm{HCl} \text { e } \mathrm{CH}_{3} \mathrm{COOH} \text { e suas misturas } \\
\text { objetivando alcanças as melhores extrações assistidas por } \\
\text { ultrassom possíveis }\end{array}$ & 57 \\
\hline $\mathrm{Cu}, \mathrm{Mn}, \mathrm{Ni}$ e $\mathrm{Zn}$ & Rações para frango & FAAS & $\begin{array}{l}\text { Otimizar as proporções da fase líquida (soluções de } \mathrm{HNO}_{3}, \mathrm{HCl} \text { e } \\
\mathrm{CH}_{3} \mathrm{COOH} \text { ) de suspensões da amostra de forma a promover as } \\
\text { maiores percentagens de recuperação }\end{array}$ & 58 \\
\hline $\mathrm{Fe}, \mathrm{Zn}, \mathrm{Mn}, \mathrm{Ni}$ e Co & $\begin{array}{l}\text { Chorume de aterro } \\
\text { sanitário }\end{array}$ & FAAS & $\begin{array}{l}\text { Encontrar a melhor proporção de soluções de reagentes }\left(\mathrm{H}_{2} \mathrm{O}_{2} \text {, }\right. \\
\mathrm{NaOH} \text { e tampão borato) que promova a foto-oxidação eficiente } \\
\text { das amostras de chorume visando obter digeridos adequados } \\
\text { para a determinação de metais }\end{array}$ & 59 \\
\hline $\mathrm{Fe}$ & Folhas de mandioca & FAAS & $\begin{array}{l}\text { Estudar as proporções de soluções que compõem a fase líquida } \\
\text { de suspensões diretamente introduzidas no espectrômetro de } \\
\text { forma a garantir a melhor sensibilidade possível }\end{array}$ & 62 \\
\hline
\end{tabular}




\section{Agradecimentos}

Os autores deste artigo agradecem ao Conselho Nacional de Desenvolvimento Científico e Tecnológico (CNPq), Fundação de Amparo à Pesquisa do estado da Bahia (FAPESB) e a Coordenação de Aperfeiçoamento de Pessoal de Nível Superior (CAPES) pelo suporte financeiro.

\section{Referências Bibliográficas}

${ }^{1}$ Bezerra, M. A.; Santelli, R. E.; Oliveira, E. P.; Villar, L. S.; Escaleira, L. A. Response surface methodology (RSM) as a tool for optimization in analytical chemistry. Talanta 2008, 76, 965. [CrossRef] [PubMed]

${ }^{2}$ Massart, D. L.; Vaneginste, B. G. M.; Buydens, J. M. C.; Jong, S.; Lewis, P. J.; Smeyers-Verberke, J.; Handbook of Chemometrics and Qualimetrics, 1st ed., Part A, vol. 20B, Elsevier: Amsterdam, 1997

${ }^{3}$ Eriksson, L.; Johansson, E.; Wikström, C. Mixture design-design generation, PLS analysis, and model usage. Chemometrics and Intelligent Laboratory Systems 1998, 43, 1. [CrossRef]

${ }^{4}$ Barros Neto, B.; Scarmínio, I. S.; Bruns, R. E.; Como fazer experimentos: aplicações na ciência e na indústria, 4a. ed., Bookman: Porto Alegre, 2010

${ }^{5}$ Reis, C.; de Andrade, J. C. Planejamento experimental para misturas usando cromatografia em papel. Química Nova 1996, 19, 313. [Link]

${ }^{6}$ Calado, V.; Montgomery, D.; Planejamento de experimentos usando o statistica, 1a. ed., E-papers: Rio de Janeiro, 2003.

${ }^{7}$ Novaes, C. G.; Bezerra, M. A.; da Silva, E. G. P.; dos Santos, A. M. P.; Romão, I. L. S.; Santos Neto, J. H. A review of multivariate designs applied to the optimization of methods based on inductively coupled plasma optical emission spectrometry (ICP
OES). Microchemical Journal 2016, 128, 331. [CrossRef]

${ }^{8}$ Sahin, Y. B.; Demirtas, E. A.; Burnak, N. Mixture designs: a review of recent applications in the food industry. Pamukkale University Muhendislik Bilimleri Dergisi 2016, 22, 297. [CrossRef]

${ }^{9}$ Armstrong, N. A. Pharmaceutical Experimental Design and Interpretation, 2nd. ed., CRC Press/Taylor \& Francis: Boca Raton FL, 2006

${ }^{10}$ Ferreira, S. L. C.; Bruns, R. E.; da Silva, E. G. P.; dos Santos, W. N. L.; Quintella, C. M.; David, J. M.; de Andrade, J. B.; Breitkreitz, M. C.; Jardim, I. C. S. F.; Barros Neto, B. Statistical designs and response surface techniques for the optimization of chromatographic systems. Journal of chromatography A 2007, 1158, 2. [CrossRef] [PubMed]

${ }^{11}$ Voinovich, D.; Campisi, B.; Phan-Tan-Luu, R. in Comprehensive Chemometrics: Chemical and Biochemical Data Analysis; Brown, S. D.; Tauler, R.; Walczak, B., eds., Elsevier: Amsterdam, 2009, vol. 1.

${ }^{12}$ Cafaggi, S.; Leardi, R.; Parodi, B.; Caviglioli, G.; Bignardi, G. An example of application of a mixture design with constraints to a pharmaceutical formulation. Chemometrics and Intelligent Laboratory Systems 2003, 65, 139. [CrossRef]

${ }^{13}$ Garcia, L. M. Z.; de Oliveira, T. F.; Soares, P. K.; Bruns, R. E.; Scarminio, I. S. Statistical mixture design - Principal component determination of synergic solvent interactions for natural product extractions. Chemometrics and Inteligent Laboratory Systems 2010, 103, 1. [CrossRef]

${ }^{14}$ Fourdinier, M.; Bostyn, S.; Delépée, R.; Fauduet, $H$. Interest of a chemometric approach in understanding the retention behaviour of three columns in hydrophilic interaction liquid chromatography: Application to the separation of glycerol carbonate, glycerol and urea. Talanta 2010, 81, 1281. [CrossRef] [PubMed] 
${ }^{15}$ Chen, R.; Zhang, Z.; Feng, C.; Hu, K.; Li, M.; Li, Y.; Shimizu, K.; Chen, N.; Sugiura, N. Application of simplex-centroid mixture design in developing and optimizing ceramic adsorbent for As(V) removal from water solution. Microporous and Mesopororous Materials 2010, 131, 115. [CrossRef]

${ }^{16}$ de Pinho, G. P.; Neves, A. A.; de Queiroz, M. E. L. R.; Silvério, F. O. Pesticide determination in tomatoes by solid-liquid extraction with purification at low temperature and gas chromatography. Food Chemistry 2010, 121, 251. [CrossRef]

${ }^{17} \mathrm{Gu}, \mathrm{C}$; He, J.; Jia, J.; Fang, N.; Simmons, R.; Shamsi, S. A. Surfactant-bound monolithic columns for separation of proteins in capillary high performance liquid chromatography. Journal of Chromatogaphy A 2010, 1217, 530. [CrossRef] [PubMed]

${ }^{18}$ Nano, R.M.W.; Bruns, R.E.; Ferreira, S.L.C.; Baccan, N.; Cadore, S. Statistical mixture design development of digestion methods for Oyster tissue using inductively coupled plasma optical emission spectrometry for the determination of metallic ions. Talanta 2009, 80, 559. [CrossRef] [PubMed]

${ }^{19}$ Breitkreitz, M. C.; Jardim, I. C. S. F.; Bruns, R. E. Combined column-mobile phase mixture statistical design optimization of high-performance liquid chromatographic analysis of multicomponent systems. Journal of Chromatography A 2009, 1216, 1439. [CrossRef] [PubMed]

${ }^{20}$ Rezić, I. Optimization of ultrasonic extraction of 23 elements from cotton. Ultrasonics Sonochemistry 2009, 16, 63. [CrossRef] [PubMed]

${ }^{21}$ Stefan, A.R.; Dockery, C.R.; Baguley, B.M.; Vann, B. C; Nieuwland, A. A.; Hendrix, J. E.; Morgan, S. L. Microextraction, capillary electrophoresis, and mass spectrometry for forensic analysis of azo and methine basic dyes from acrylic fibers. Analytical and Bioanalytical Chemistry 2009, 394, 2087. [CrossRef] [PubMed]

${ }^{22}$ Soares, P. K.; Bruns, R. E.; Scarminio, I. S. Statistical mixture design investigation of fractionated and total extracts from Erythrina speciosa Andrews leaves. Journal of Separation Science 2009, 32, 644. [CrossRef] [PubMed]

${ }^{23}$ Soares, P. K.; Scarminio, I. S. Multivariate chromatographic fingerprint preparation and authentication of plant material from the genus Bauhinia. Phytochemical Analysis 2008, 19, 78. [CrossRef] [PubMed]

${ }^{24}$ Delaroza, F.; Scarminio, I. S. Mixture design optimization of extraction and mobile phase media for fingerprint analysis of Bauhinia variegata L. Journal of Separation Science 2008, 31, 1034. [CrossRef] [PubMed]

${ }^{25}$ Soares, P. K.; Bruns, R. E.; Scarminio, I. S. Statistical mixture design - varimax factor optimization for selective compound extraction from plant material. Analytica Chimica Acta 2008, 613, 48. [CrossRef] [PubMed]

${ }^{26}$ Soares, P. K.; Bruns, R. E.; Scarminio, I. S. Statistical mixture design - principal component optimization for selective compound extraction from plant material. Journal of Separation Science 2007, 30, 3302. [CrossRef] [PubMed]

${ }^{27}$ de Almeida, A. A.; Scarminio, I. S. Statistical mixture design optimization of extraction media and mobile phase compositions for the characterization of green tea. Journal of Separation Science 2007, 30, 414. [CrossRef] [PubMed]

${ }^{28}$ Borges, C. N.; Breitkreitz, M. C.; Bruns, R.E.; Silva, L. M. C.; Scarminio, I. S. Unreplicated split-plot mixture designs and statistical models for optimizing mobile chromatographic phase and extraction solutions for fingerprint searches. Chemometrics and Inteligent Laboratory System 2007, 89, 82. [CrossRef]

${ }^{29}$ Ferreirós, N.; Iriarte, G.; Alonso, R.M.; Jiménez, R.M. Development of a solid phase extraction procedure for HPLC-DAD determination of several angiotensin II receptor antagonists in human urine using mixture design. Talanta 2007, 73, 748. [CrossRef] [PubMed]

${ }^{30}$ Borges, C. N.; Bruns, R. E.; Almeida, A. A.; Scarminio, I. S. Mixture-mixture design for 
the fingerprint optimization of chromatographic mobile phases and extraction solutions for Camellia sinensis. Analytica Chimica Acta 2007, 595, 28. [CrossRef] [PubMed]

${ }^{31}$ Furlanetto, S.; Orlandini, S.; Marras, A. M.; Mura, P.; Pinzauti, S. Mixture design in the optimization of a microemulsion system for the electrokinetic chromatographic determination of ketorolac and its impurities: Method development and validation. Electrophoresis 2006, 27, 805. [CrossRef] [PubMed]

${ }^{32}$ Pages, G.; Mazarin, M.; Sergent, M.; PhanTan-Luu, R.; Delaurent, C. Optimization of the assay of naphthodianthrones in dry St John's wort extract by reversed-phase liquid chromatography. Analytical and Bioanalytical Chemistry 2006, 385, 716. [CrossRef] [PubMed]

${ }^{33}$ Cutroneo, P.; Beljean, M.; Phan Tan Luu, R.; Siouffi, A.-M. Optimization of the separation of some psychotropic drugs and their respective metabolites by liquid chromatography. Journal of Pharmaceutical and Biomedical Analysis 2006, 41, 333. [CrossRef] [PubMed]

${ }^{34}$ Navarro, P.; Raposo, J. C.; Arana, G.; Etxebarria, N. Optimisation of microwave assisted digestion of sediments and determination of $\mathrm{Sn}$ and $\mathrm{Hg}$. Analytical Chimica Acta 2006, 566, 37. [CrossRef]

${ }^{35}$ Zhang, Y. P.; Gong, W. J.; Lee, K. P.; Choi, S. H.; Gopalan, A. T.; Yuan, Z. B. ComputerAssisted Modeling, Prediction, and Multifactor Optimization of Hydrophobic Compounds in Liquid Chromatography. Microchimica Acta 2005, 152, 113. [CrossRef]

${ }^{36}$ Cámara, M. S.; Mastandrea, C.; Goicoechea, H. C. Chemometrics-assisted simple UV-spectroscopic determination of carbamazepine in human serum and comparison with reference methods. Journal of Biochemical and Biophysical Methods 2005, 64, 153. [CrossRef] [PubMed]

${ }^{37}$ Cortazar, E.; Bartolomé, L.; Delgado, A.; Etxebarria, N.; Fernández, Usobiaga, A.;
Zuloaga, O. Optimisation of microwaveassisted extraction for the L.A.; determination of nonylphenols and phthalate esters in sediment samples and comparison with pressurised solvent extraction. Analytica Chimica Acta 2005, 534,247. [CrossRef]

${ }^{38}$ Ferreira, L. F. P.; Taqueda, M. E.; Vitolo, M.; Converti, A.; Pessoa, A. Liquid-liquid extraction of commercial glucose oxidase by reversed micelles. Journal of Biotechnology 2005, 116, 411. [CrossRef] [PubMed]

${ }^{39}$ Coscione, A. R.; de Andrade, J. C.; May, G. M. O modelamento estatístico de misturas: experimento tutorial usando voltametria de redissolução anódica. Química Nova 2005, 28, 1116. [CrossRef]

${ }^{40}$ Bortoloti, J. A.; Bruns, R. E.; de Andrade, J. C.; Vieira, R. K. Split-plot design optimization for trace determination of lead by anodic stripping voltammetry in a homogeneous ternary solvent system. Chemometrics and Inteligent Laboratory System 2004, 70, 113. [CrossRef]

${ }^{41}$ Periago, M. J.; Rincón, F.; Agüera, M. D.; Ros, G. Mixture Approach for Optimizing Lycopene Extraction from Tomato and Tomato Products. Journal of Agricultural and Food Chemistry 2004, 52, 5796. [CrossRef] [PubMed]

${ }^{42}$ Palasota, J. M.; Deming, S. N. Mixture designs applied to the study of the liquid chromatographic separation of Iphenylalanine, I-tyrosine and I-tryptophan. Analytica Chimica Acta 1993, 270, 13. [CrossRef]

${ }^{43}$ Wieling, J.; Dijkstra, H.; Mensink, C. K.; Jonkman, J. H. G.; Coenegracht, P. M. J.; Duineveld, C. A. A.; Doornbos, D. A. Chemometrics in bioanalytical sample preparation: A fractionated combined mixture and factorial design for the modelling of the recovery of five tricyclic amines from plasma after liquid-liquid extraction prior to high-performance liquid chromatography. Journal of Chromatography A 1993, 629, 181. [CrossRef] [PubMed] 
${ }^{44}$ Nezhadali, A.; Sadeghzadeh, S. Optimization of stripping voltammetric sensor by mixture design-artificial neural network-genetic algorithm for determination of trace copper(II) based on iodoquinolcarbon nanotube modified carbon paste electrode. Sensors and Actuators B 2016, 224, 134. [CrossRef]

${ }^{45}$ Orlandini, S.; Pasquini, B.; Stocchero, M.; Pinzauti, S.; Furlanetto, S. An integrated quality by design and mixture-process variable approach in the development of a capillary electrophoresis method for the analysis of almotriptan and its impurities. Journal of Chromatography A 2014, 1339, 200. [CrossRef] [PubMed]

${ }^{46}$ Lonni, A. A. S. G.; Longhini, R.; Lopes, G. C.; de Mello, J. C. P.; Scarminio, I. S. Statistical mixture design selective extraction of compounds with antioxidant activity and total polyphenol content from Trichilia catigua. Analytica Chimica Acta 2012, 719, 57. [CrossRef] [PubMed]

${ }^{47}$ Seabra, I.J.; Braga, M.E.M.; de Sousa, H.C. Statistical mixture design investigation of $\mathrm{CO}_{2}$-Ethanol- $\mathrm{H}_{2} \mathrm{O}$ pressurized solvent extractions from tara seed coat. The Journal of Supercritical Fluids 2012, 64, 9. [CrossRef]

${ }^{48}$ Pauli, E. D.; Malta, G. B.; Sanchez, P. M.; Moreira, I. C.; Scarminio, I. S. Mixture design analysis of solvent extractor effects on epicatechin, epigallocatechin gallate, epigallocatechin and antioxidant activities of the Camellia sinensis L. leaves. Analytical Chemistry Research 2014, 2, 23. [CrossRef]

${ }^{49}$ Soares, D. X.; Scarminio, I. S.; Bruns, R. E. Mixture designs for exploring class diversity and metabolite fingerprinting: An efficient column chromatographic strategy. Analytica Chimica Acta 2011, 702, 288. [CrossRef] [PubMed]

${ }^{50}$ Farajzadeh, M. A.; Khoshmaram, L. Development of dispersive liquid-liquid micro-extraction technique using ternary solvents mixture followed by heating for the rapid and sensitive analysis of phthalate esters and di(2-ethylhexyl) adipate. Journal of
Chromatography A 2015, 1379, 24. [CrossRef] [PubMed]

${ }^{51}$ dos Santos, L.; dos Santos, Q. O.; Moreno, I.; Novaes, C. G.; dos Santos, M. J. S.; Bezerra, M. A. Multivariate optimization of a simultaneous cloud point extraction procedure of $\mathrm{Cd}, \mathrm{Cu}$ and $\mathrm{Ni}$ from sediments samples and determination by ICP OES. Journal of the Brazilian Chemical Society 2016, 28, 745. [CrossRef]

${ }^{52}$ Castro, J. T.; Bezerra, M. A.; Lima Neto, M. A.; Korn, M. G. A.; Novaes, C.G.; Santelli, R.E. Use of a constrained mixture design to optimize a procedure for closed vessel microwave-assisted digestion of vegetal leaves. Current Microwave Chemistry 2017, 4, 16. [CrossRef]

${ }^{53}$ Cardozo, M. C.; Cavalcante, D. D.; Silva, D. L. F.; dos Santos, W. N. L.; Bezerra, M. A. Multivariate optimization of a method for antimony determination by hydride generation atomic fluorescence spectrometry in hair samples of patients undergoing chemotherapy against Leishmaniasis. Anais da Academia Brasileira de Ciências 2016, 88, 1179. [CrossRef] [PubMed]

${ }^{54}$ Moreira, I.; Scheel; G. L.; Hatumura; P. H.; Scarminio, I. S. Efeito do solvente na extração de ácidos clorogênicos, cafeína e trigonelina em Coffea arabica. Química Nova 2014, 37, 39. [CrossRef]

${ }^{55}$ Felix, A. C. S.; Alvarez, L. D. G.; Santana, R. A.; Valasques Júnior, G. L.; Bezerra, M. A.; de Oliveira Neto, N. M.; de Oliveira Lima, E.; de Oliveira Filho, A. A.; Franco, M.; do Nascimento Júnior, B. B. Application of experimental designs to evaluate the total phenolics contente and antioxidante activity of cashew apple bagasse, Revista Mexicana de Ingenieria Química, 2018, 17, 165.

${ }^{56}$ Carvalho, A. L.; Santana, S. M. F.; Silva, C. F.; Pepe, I. M.; Bezerra, M. A.; Quintella, C. M.; Teixeira, L. S. G. Evaluation of the oxidative stability of biodiesel blends from soybean, tallow and castor bean using experimental mixture design. Journal of the Brazilian Chemical Society, 2013, 24, 1373. [CrossRef] 
${ }^{57}$ Santos, W. P. C.; Castro, J. T.; Bezerra, M. A.; Fernandes, A. P.; Ferreira, S. L. C.; Korn, M. G. A. Application of multivariate optimization in the development of an ultrasound-assisted extraction procedure for multielemental determination in bean seeds samples using ICP OES. Microchemical Journal 2009, 91, 153. [CrossRef]

${ }^{58}$ Barros, J. M.; Bezerra, M. A.; Valasques, G. S.; do Nascimento Jr., B. B.; Souza, A. S.; de Aragão, N. M. Multivariate optimization of an ultrasound-assisted extraction procedure for $\mathrm{Cu}, \mathrm{Mn}, \mathrm{Ni}$ and $\mathrm{Zn}$ determination in ration to chickens. Anais da Academia Brasileira de Ciências 2013, 85, 891. [CrossRef] [PubMed] ${ }^{59}$ M. A.; Bezerra, A. D. S.; Souza, R. V.; Oliveira, D. M.; Oliveira, L. A. M. Cardoso, Sousa Filho H. R. Use of Doehlert and constrained mixture designs in the development of a photo-oxidation procedure using UV radiation $/ \mathrm{H}_{2} \mathrm{O}_{2}$ for decomposition of landfill leachate samples and determination of metals by flame atomic absorption spectrometry. Anais da Academia Brasileira de Ciências 2015, 87, 3. [CrossRef] [PubMed] ${ }^{60}$ Cano, C. B.; Felsner, M. L.; Bruns, R. E.; Matos, J. R.; Almeida-Muradian, L. B.;
Optimization of mobile phase for separation of carbohydrates in honey by high performance liquid chromatography using a mixture design. Journal of the Brazilian Chemical Society 2006, 17, 588. [CrossRef]

${ }^{61}$ Bezerra, M. A.; Castro, J. T.; R. C.; Macedo, da Silva, D. G. Use of constrained mixture design for optimization of method for determination of zinc and manganese in tea leaves employing slurry sampling. Analytica Chimica Acta 2010, 670, 33. [CrossRef] [PubMed]

${ }^{62}$ Dias, F. S.; Alves, L. S.; dos Santos, W. N. L.; Bruns, R. E.; Bezerra, M. A. Mixture Design Optimization of an Analytical Procedure for Iron Extraction and Determination From Cassava Leaves by Slurry Sampling Flame Atomic Absorption Spectrometry. Spectroscopy Letters 2011, 44, 388. [CrossRef]

${ }^{63}$ Novaes, C. G.; Yamaki, R. T.; de Paula, V. F.; do Nascimento Júnior, B. B.; Barreto, J. A.; Valasques, G. S.; Bezerra, M. A. Otimização de Métodos Analíticos Usando Metodologia de Superfícies De Resposta - Parte I: Variáveis de Processo Revista Virtual de Quimica 2017, 9, 1184. [CrossRef] 